\title{
Field Demonstrations of Five Geophysical Methods that Could Be Used to Characterize Deposits of Alluvial Aggregate
}

Scientific Investigations Report 2007-5226 


\section{Field Demonstrations of Five Geophysical Methods that Could Be Used to Characterize Deposits of Alluvial Aggregate}

By K.J. Ellefsen, B.L. Burton, J.E. Lucius, S.S. Haines, D.V. Fitterman, J.A. Witty,

D. Carlson, B. Milburn, and W.H. Langer

Scientific Investigations Report 2007-5226 


\section{U.S. Department of the Interior DIRK KEMPTHORNE, Secretary}

\section{U.S. Geological Survey \\ Mark D. Myers, Director}

\section{U.S. Geological Survey, Reston, Virginia: 2007}

For product and ordering information:

World Wide Web: http://www.usgs.gov/pubprod

Telephone: 1-888-ASK-USGS

For more information on the USGS--the Federal source for science about the Earth, its natural and living resources, natural hazards, and the environment:

World Wide Web: http://www.usgs.gov

Telephone: 1-888-ASK-USGS

Any use of trade, product, or firm names is for descriptive purposes only and does not imply endorsement by the U.S. Government.

Although this report is in the public domain, permission must be secured from the individual copyright owners to reproduce any copyrighted materials contained within this report.

Suggested citation:

Ellefsen, K.J., Burton, B.L., Lucius, J.E., Haines, S.S., Fitterman, D.V., Witty, J.A., Carlson, D., Milburn, B., and Langer, W.H., 2007, Field demonstrations of five geophysical methods that could be used to characterize deposits of alluvial aggregate: U.S. Geological Survey Scientific Investigations Report 2007-5226, 20 p. 


\section{Contents}

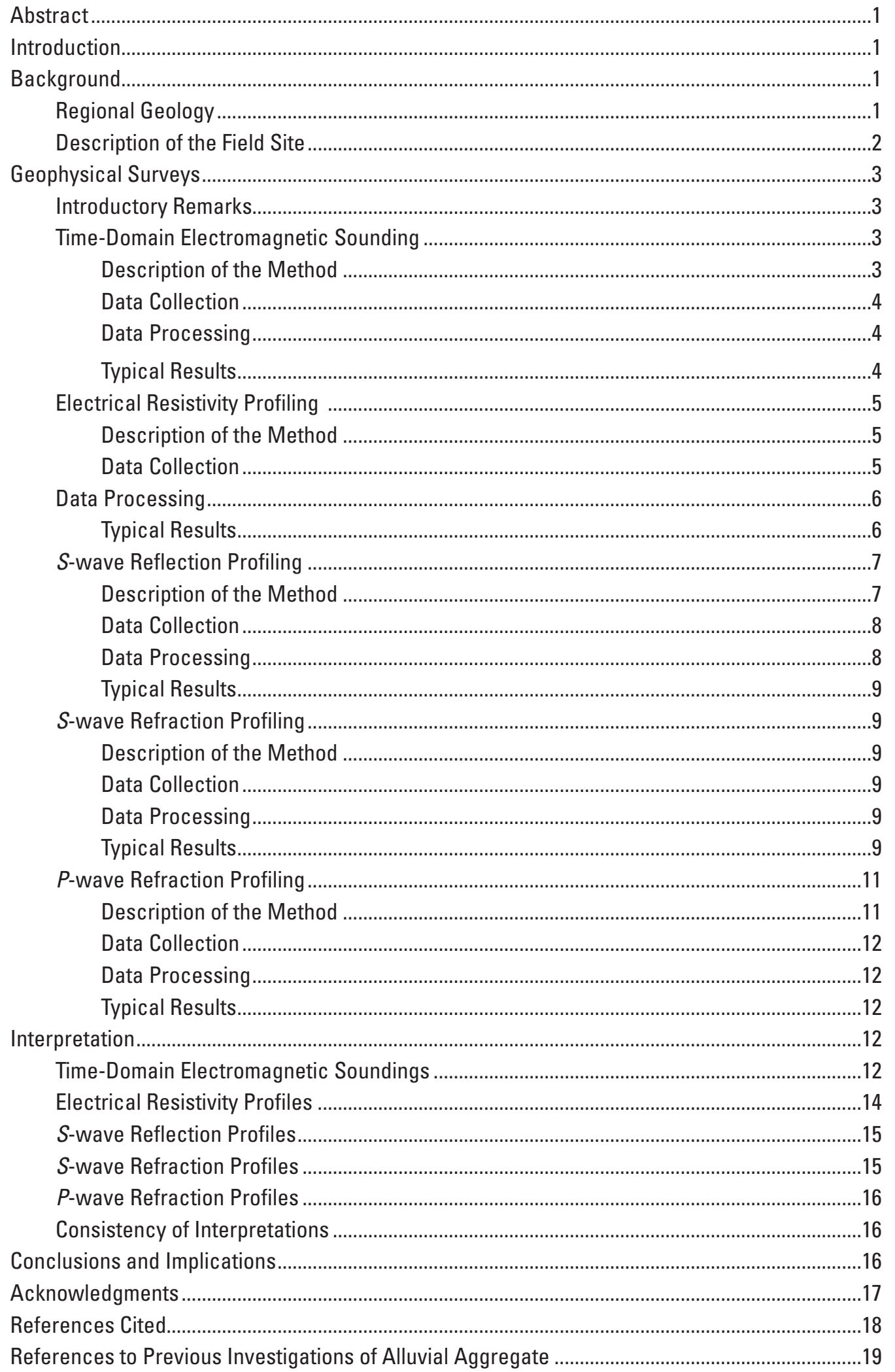




\section{Plates}

1. Locations of geophysical profiles, geophysical soundings, and drill holes

2. Selected drill-hole logs

3. Geophysical and geological cross sections

\section{Figures}

1. Generalized stratigraphic column near the field site .2

2. Photograph showing a portion of the field site, looking northwesterly from Road 1 ........2

3. Photograph showing receiver coil and data recorder used for TEM soundings .3

4. Graphs showing typical results from a TEM sounding. A, Apparent resistivities and their standard deviations. $B$, Electromagnetic model estimated from the apparent resistivities.

5. Photographs showing $A$, Electrode and cable attachment used for electrical resistivity profiling. $B$, Electrodes and the associated cables used to collect one set of measurements. $C_{\text {, Instrument used to collect and record the electrical }}$ resistivity data.

6. Typical results from an electrical resistivity profile

7. Photographs showing equipment used for $S$-wave seismic reflection and refraction profiling. $A$, Clog source. $B$, Golf shoe source. $C$, Geophone used to detect the $S$-wave. $D$, Seismograph used to record the time-varying voltages generated by the geophones

8. $S$-wave seismic reflection and refraction data recorded in the farm field .....................8

9. Typical results from an $S$-wave reflection profile

10. Typical results from an $S$-wave refraction profile. $A$, Measured and calculated traveltimes. $B$, Cross section showing the $S$-wave velocities estimated from the measured traveltimes. $C$, Cross section showing the number of rays passing through each block in the seismic cross section.

11. Photographs showing equipment used for $\mathrm{P}$-wave refraction profiling. $A$, Truckmounted, weight-drop source. $B$, Close-up view of the truck-mounted, weight-drop source. $C, 9.1-\mathrm{kg}$ sledgehammer source. $D$, Geophone used to detect $P$-waves

12. $P$-wave refraction data recorded in the farm field

13. Graphs $A$ and $B$, showing interpretations of two time-domain electromagnetic soundings, including the driller's logs from the holes that are closest to the soundings 


\section{Tables}

1. Acquisition parameters for the electrical resistivity profiles..........................................

2. Acquisition parameters for the $S$-wave seismic reflection and refraction profiling .......8

3. Procedures used to process the $S$-wave reflection data................................................

4. Acquisition parameters for the $P$-wave refraction profiling ...........................................12

5. Summary of the field demonstrations, indicting whether a geologic or hydrologic feature was detected or measured by each geophysical method.. 



\title{
Field Demonstrations of Five Geophysical Methods that Could Be Used to Characterize Deposits of Alluvial Aggregate
}

\author{
By K.J. Ellefsen, B.L. Burton, J.E. Lucius, S.S. Haines, D.V. Fitterman, J.A. Witty, D. Carlson, B. Milburn, and \\ W.H. Langer
}

\section{Abstract}

Personnel from the U.S. Geological Survey and Martin Marietta Aggregates, Inc., conducted field demonstrations of five different geophysical methods to show how these methods could be used to characterize deposits of alluvial aggregate. The methods were time-domain electromagnetic sounding, electrical resistivity profiling, $S$-wave reflection profiling, $S$-wave refraction profiling, and $P$-wave refraction profiling. All demonstrations were conducted at one site within a river valley in central Indiana, where the stratigraphy consisted of 1 to 2 meters of clay-rich soil, 20 to 35 meters of alluvial sand and gravel, 1 to 6 meters of clay, and multiple layers of limestone and dolomite bedrock. All geophysical methods, except time-domain electromagnetic sounding, provided information about the alluvial aggregate that was consistent with the known geology. Although time-domain electromagnetic sounding did not work well at this site, it has worked well at other sites with different geology. All of these geophysical methods complement traditional methods of geologic characterization such as drilling.

\section{Introduction}

Companies that mine aggregate need to know the geology of a deposit when they are determining whether it can be profitably mined, when they are selecting methods to mine it, and when they are calculating their reserves. The geology of a deposit can be determined, in part, with surface geophysical surveys. For these surveys, instruments on the surface of the ground generate signals such as sound waves, radio waves, or electrical currents. These signals are sent into the ground where they interact with geologic heterogeneity. The modified signals return to the ground surface where they are detected and recorded by other instruments. These modified signals are then processed to develop a geophysical cross section of the ground, and this cross section is interpreted in terms of the geology.
About 15 geophysical investigations of aggregate deposits have been published (Ellefsen and others, 1998; Ellefsen and others, 2005; and the section "References to Previous Investigations of Alluvial Aggregate"). These investigations, with one exception, focused on obtaining geologic information using just one geophysical method. The exception is Ellefsen and others (1998) who conducted demonstrations of four different geophysical methods to show how they could characterize an aggregate deposit. These four methods were time-domain electromagnetic sounding, frequency-domain electromagnetic profiling, electrical resistivity sounding, and ground-penetrating radar.

In this study, five different geophysical methods are demonstrated to show how they could characterize an aggregate deposit. These five methods, with one exception, are different from the four methods that were previously demonstrated by Ellefsen and others (1998). The five methods are time-domain electromagnetic sounding, electrical resistivity profiling, $S$-wave reflection profiling, $S$-wave refraction profiling, and $P$-wave refraction profiling. These field demonstrations show the advantages and limitations of the various methods.

This study involved personnel from both the U.S. Geological Survey and Martin Marietta Aggregates, Inc. The field site for the study was leased for mining by Martin Marietta, and so the exact location of the field site (that is, the latitude and the longitude) is not stated in this report because of an informal non-disclosure agreement. For the same reason, the names of the roads adjoining the field site are altered for this report. Nonetheless, the approximate location of the field site is stated, and the geology of the site is fully described.

\section{Background}

\section{Regional Geology}

The field site is located near Columbus, Indiana (pl. 1), and is within the physiographic area called the "Scottsburg Lowland" (Gray, 2000). The field site lies within the Flatrock 
River Valley whose sediments were deposited by meltwater of the Wisconsin glacier about 15,000 to 20,000 years ago (National Cooperative Soil Survey, 2002).

The stratigraphy pertinent to this study is shown in figure 1 . The deepest sedimentary bedrock layer is shale and shaley limestone of the Upper Ordovician Series, which is $60 \mathrm{~m}$ or more thick (Thompson, 1996). The next overlying layer is limestone and dolomite of the Silurian System, which is as much as $45 \mathrm{~m}$ thick (Maier, 2004). The next layer is limestone and dolomite of the Middle Devonian Series, which is as much as $23 \mathrm{~m}$ thick. These sedimentary layers dip gently to the west into the Illinois Basin tectonic feature (Maier, 2004; Rupp, 1997). The limestone and dolomite layers form a freshwater aquifer.

Overlying the bedrock are three layers of unconsolidated sediments (fig. 1). The deepest is a clay layer, which is 1 to $6 \mathrm{~m}$ thick (Maier, 2004). The next layer is alluvium, which is 15 to $30 \mathrm{~m}$ thick and mostly consists of sand and gravel. This alluvium is outwash from the Wisconsin glaciation and was deposited mostly as valley train (Indiana University, 2005). (Valley train is defined as a long, narrow body of outwash that was deposited in a river valley, far beyond the margin of an active glacier [Bates and Jackson, 2005].) The uppermost layer is soil, which is 1 to $2 \mathrm{~m}$ thick and is characterized as silt loam, silty loam, and silty clay loam (National Cooperative Soil Survey, 2002).

\begin{tabular}{|c|c|c|c|c|c|}
\hline \multicolumn{2}{|c|}{ Time Unit } & \multirow[t]{2}{*}{ Age (Ma) } & \multirow{2}{*}{$\begin{array}{l}\text { Thickness } \\
\text { (m) }\end{array}$} & \multicolumn{2}{|c|}{ Lithology } \\
\hline Period & Epoch & & & & \\
\hline \multirow{3}{*}{ Quaternary } & \multirow{3}{*}{ Pleistocene } & \multirow{3}{*}{$0.015-0.020$} & $1-2$ & loamy soil & \\
\hline & & & $15-30$ & $\begin{array}{l}\text { sand } \\
\text { and } \\
\text { gravel }\end{array}$ & 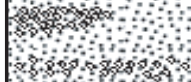 \\
\hline & & & $1-6$ & till, clay & \\
\hline Devonian & & $360-410$ & up to 23 & $\begin{array}{l}\text { limestone } \\
\text { and } \\
\text { dolomite }\end{array}$ & 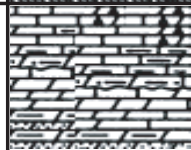 \\
\hline Silurian & & $410-440$ & up to 45 & $\begin{array}{l}\text { limestone } \\
\text { and } \\
\text { dolomite }\end{array}$ & 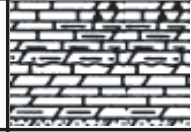 \\
\hline Ordovician & Late & $440-446$ & 60 or more & $\begin{array}{l}\text { shale and } \\
\text { shaley } \\
\text { limestone }\end{array}$ & 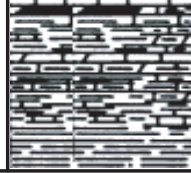 \\
\hline
\end{tabular}

Figure 1. Generalized stratigraphic column near the field site (adapted from Indiana University, 1986; and Thompson, 1996).

\section{Description of the Field Site}

The field site is in farmland (pl. 1), which is bordered on its east side by the Flatrock River; on its north side by Road 3; on its west side by Roads A, 2, and B; and on its south side by Road 1. Road 3 had moderate automobile and truck traffic; all other roads had little traffic. Along Road B are electrical power lines and a buried telephone line; on the east side of this road is a farmhouse and associated farm buildings. Near the intersection of Roads A and 2 is an electrical power station, which is not shown on the plate. Along Road A are electrical power lines; on the east side of this road is a farmhouse and associated farm buildings. Between this farmhouse and a pivot irrigator, which is in the middle of the field, is an electrical power line that is buried beneath the ground surface.

The farmland at the field site is practically flat (fig. 2). Because the geophysical data were collected during March, the farm fields were not planted with crops but were littered with remnants of crops from the previous year (for example, parts of corn stalks). The soil in the fields was dry and somewhat hard because neither rain nor snow had fallen recently. On the southeastern side of the farm field, the soil was covered by sand, which was apparently deposited by the Flatrock River during a recent flood. The farmhouse yards were fenced with barbed wire.

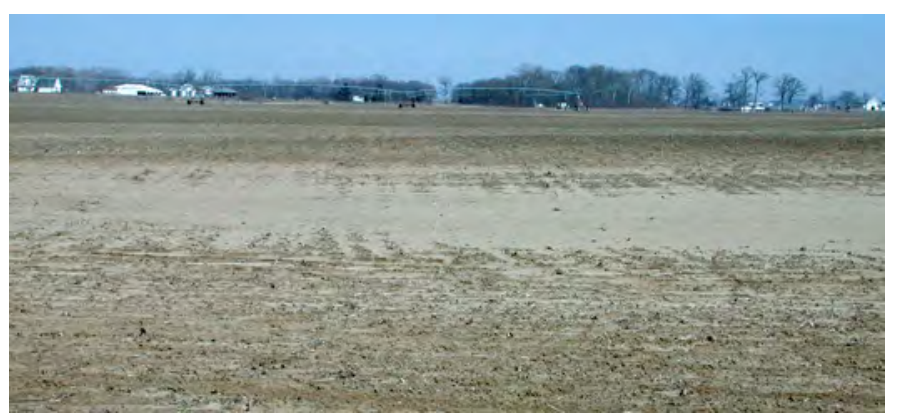

Figure 2. A portion of the field site, looking northwesterly from Road 1 (pl. 1). In the foreground is sand, which is overlying the soil. In the distance is the pivot irrigator.

The field site was drilled, and the cuttings were logged to determine the stratigraphy. The locations of the drill holes are shown on plate 1. Drilling stopped either when the drill penetrated the clay layer beneath the sand and gravel layer (fig. 1) or when the drill stem reached its maximum length, $30.5 \mathrm{~m}$ $(100 \mathrm{ft})$. For the latter case, the drill logs lack information about the stratigraphy at depths greater than $30.5 \mathrm{~m}(100 \mathrm{ft})$. Beneath the soil, the logs record the dominant sediments within depth intervals of about $3 \mathrm{~m} \mathrm{(10} \mathrm{ft)}$.

To help visualize the geology, selected logs are plotted along two profiles whose locations are shown on plate 1 . Profile $L L^{\prime}$ is oriented along the river valley, whereas profile $M M^{\prime}$ is oriented across the river valley. In every $\log (\mathrm{pl} .2)$, the top layer is soil. Its thickness ranges from 0.6 to $2.4 \mathrm{~m} \mathrm{(2}$

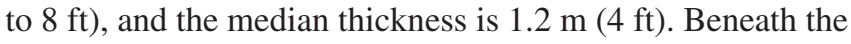
soil is a layer of coarse gravel and sand. Its thickness ranges from 3.0 to $11.6 \mathrm{~m}$ ( 10 to $38 \mathrm{ft}$ ), and the median thickness is $5.2 \mathrm{~m}(17 \mathrm{ft})$. Beneath the coarse gravel and sand is a layer of fine gravel and sand, except in drill holes 28 and 29. Its thickness ranges from 0.0 to $12.2 \mathrm{~m}$ ( 0 to $40 \mathrm{ft}$ ), and the median 
thickness is $6.1 \mathrm{~m}(20 \mathrm{ft})$. Beneath the fine gravel and sand is a layer of sand, which includes gravel and cobbles in a few drill holes. Its thickness ranges from 4.9 to at least $21.3 \mathrm{~m} \mathrm{(16} \mathrm{to} \mathrm{at}$ least $70 \mathrm{ft}$ ).

The thicknesses of the individual layers (that is, the soil layer, the coarse gravel and sand layer, and the fine gravel and sand layer) are generally constant along $L L^{\prime}$ and $M M^{\prime}$ (pl. 2) except for a few anomalies such as drill hole 25. However, the combined thickness of the all layers increases from $L$ to $L^{\prime}-$ that is, from the southwest corner to the northeast corner of the site. If the thickness of the clay layer is approximately constant (within the range of 1 to $6 \mathrm{~m}$ [fig. 1]), then the depth to the bedrock increases from the southwest to the northeast corner. Between $M$ and $M^{\prime}$, the drill logs, except those for holes 29 and 64, extend to their maximum depth, $30.5 \mathrm{~m}$ (100 ft). Thus, the depth to the bedrock is unknown but must be greater than $30.5 \mathrm{~m}$ (100 ft).

In several drill holes, the depths to the water table were measured just after drilling (pl. 2). The depths range from 0.6 to $1.5 \mathrm{~m}$ ( 2 to $5 \mathrm{ft}$ ), and the median depth is $1.2 \mathrm{~m}(4 \mathrm{ft})$. Thus, the water table is close to the ground surface, and almost all of the alluvium is saturated. In a few drill holes, the depths to the water table were measured again, one day after the drilling. In these holes, the depths decreased about onehalf meter ( 1 to $2 \mathrm{ft}$ ), but this decrease is insignificant in this investigation.

\section{Geophysical Surveys}

\section{Introductory Remarks}

This section briefly describes the five geophysical methods - time-domain electromagnetic sounding, electrical resistivity profiling, $S$-wave reflection profiling, $S$-wave refraction profiling, and $P$-wave refraction profiling. Each description includes the procedures used to collect the data at the field site, the procedures used to process the data, and some typical results.

The goal of this effort is not to characterize the entire field site but rather to demonstrate how these five geophysical methods could be used to characterize a deposit of alluvial aggregate. Consequently, only enough data were collected to meet this goal. Thus, regions where data were collected tended to be small compared to the entire site. The exception is timedomain electromagnetic sounding: the soundings covered most of the site.

The data for all five methods were collected during March 2005. The atmospheric temperature was usually between 0 to $10^{\circ} \mathrm{C}\left(30\right.$ to $\left.50^{\circ} \mathrm{F}\right)$. The sky was clear, partly cloudy, or cloudy; the wind was calm to moderately strong. Rainfall and snowfall were insignificant. The locations of the geophysical measurements were surveyed with the Global Positioning System; the error in the locations is less than 2 centimeters.

\section{Time-Domain Electromagnetic Sounding}

\section{Description of the Method}

Time-domain electromagnetic (TEM) sounding is used to estimate how the electrical conductivity of the ground changes with depth. The technique was initially developed for mineral exploration but has become widely used in ground water, environmental, and engineering studies (McNeill, 1990). TEM soundings typically are made using an electrical wire that is laid on the ground in the shape of a square. The wire square is connected to a TEM transmitter, which produces a steady electrical current in the wire square. This current, in turn, produces a steady magnetic field. When the transmitter interrupts the current, the magnetic field starts to decay, and consequently another current is induced in the ground below the wire square. Although this induced current attempts to maintain the magnetic field, the induced current both decays and diffuses; consequently, the magnetic field continues to decay. The decay of the induced current, and hence the magnetic field, is affected by the electrical conductivity of the ground: The decay is slow where the ground is conductive, but the decay is rapid where the ground is less conductive. In other words, these interlinked processes relate the decay of the magnetic field to the electrical conductivity of the ground.

The decay of the magnetic field is monitored with a receiver coil, which is placed at the center of the wire square (fig. 3). The receiver coil generates a time-varying voltage, which is called a "transient." Because of the aforementioned processes, the transient contains information on how the conductivity of the ground varies with depth: The initial part

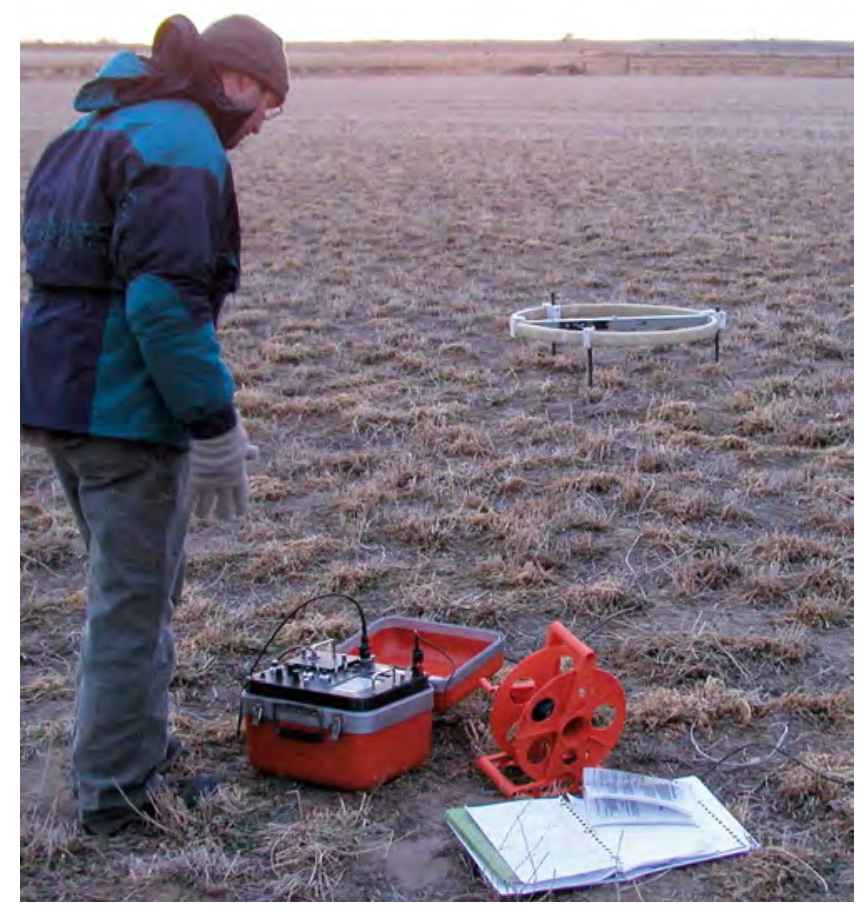

Figure 3. Receiver coil and data recorder used for TEM soundings. 
of the transient contains information about the electrical conductivity at shallow depths, whereas the later part of the transient contains information about the electrical conductivity at greater depths. Through a process called "inversion," the transient is used to estimate the electrical conductivity as a function of depth. The results of the inversion commonly are reported as the reciprocal of conductivity, which is called "resistivity." Additional information about the method is in Fitterman and Labson (2005).

\section{Data Collection}

The size of the wire square was $40 \mathrm{~m}$ by $40 \mathrm{~m}$, and the receiver coil was placed in the center of the square, a configuration called "central induction loop." The transmitter, the receiver coil, and the data recorder were a Geonics Protem 47 TEM system. To reduce errors in the data, multiple transients are recorded and averaged, using a cyclical transmitter waveform, which is called a " $50 \%$ duty-cycle square wave." The electrical current in the wire square flows in one direction for one-fourth of the period. During the next quarter period the current is turned off, and the transient is measured. The second half of the waveform is similar to the first half, except that its polarity is reversed. By increasing the period of the transmitter waveform, longer transients can be recorded, and hence information about the electrical conductivity at greater depths can be obtained. Initially, data were collected at transmitter repetition rates of 315 and $30 \mathrm{~Hz}$ (which are referred to as "ultra high frequency" and "high frequency," respectively) to estimate the transient at early and late times. Six sets of transients were typically collected at each repetition frequency so that the data could be averaged to further reduce the uncertainty in the measurements. Because of the relatively high resistivity of the alluvium, the transient decayed rapidly and the $30-\mathrm{Hz}$ data were not usable.

Twenty-eight soundings were made across the site (pl. 1). The locations of the soundings were chosen to uniformly cover the site, while avoiding underground pipes and electrical power lines that would corrupt the data.

\section{Data Processing}

The averaged transients were converted to a quantity called "apparent resistivity," using the formulas in Fitterman and Labson (2005). The apparent resistivities were plotted and visually checked for data quality (fig. $4 A$ ). With good data, the apparent resistivity changes smoothly as a function of time, and the standard deviations in the resistivity are less than about 10 to 15 percent. In the figure $4 A$ example, these two criteria were not met by four apparent resistivities, and so these four were removed from the data set before the inversion.

Despite our efforts to avoid underground pipes and power lines, several soundings were affected by the buried power line to the pivot irrigator (pl. 1). The effects appear as discontinuities in the plots of apparent resistivity, usually between 0.05 and 0.3 millisecond (ms). If the discontinuities were deemed small, the apparent resistivities were still used in the inversion.

The model used for the inversion consisted of horizontal layers; each layer was parameterized by an electrical resistivity and a thickness. The thicknesses and resistivities for the entire model were determined by a nonlinear, least-squares inversion that is implemented in commercial software available from Interpex Ltd. The starting model for the inversion was chosen according to two criteria: The model had as few layers as possible, and its calculated apparent resistivities adequately matched the measured apparent resistivities. Additional information about model calculation and data interpretation procedures can be found in Kaufman and Keller (1983), Ward and Hohmann (1988), Hohmann and Raiche (1988), and Fitterman and Labson (2005).

\section{Typical Results}

Typical results from a TEM sounding are shown in figure $4 A$. The measured apparent resistivities are about $55 \mathrm{ohm}-\mathrm{m}$ at $0.007 \mathrm{~ms}$; they rise to about $130 \mathrm{ohm}-\mathrm{m}$ at $0.14 \mathrm{~ms}$ and decrease thereafter. The associated standard deviations range from 0.1 to 10.0 percent before $0.215 \mathrm{~ms}$ and range from 20 to more than 40 percent at later times. Indeed, the later standard deviations are so large that their apparent resistivities were not used in the inversion.

Typical results of an inversion are an electromagnetic model (fig. 4B). The vertical axis indicates the depth beneath the ground surface. The horizontal axis indicates the electrical resistivity. The model shows three depth intervals within which the electrical resistivity is constant; for example, the electrical resistivity is about $50 \mathrm{ohm}-\mathrm{m}$ at depths between 0 and $14 \mathrm{~m}$. Each constant-resistivity interval corresponds to a horizontal layer in the electromagnetic model. The deepest layer extends to infinite depth. Of course, such a layer is impossible; consequently, the deepest layer should be interpreted as having a thickness that is too great to be delineated by the TEM sounding.

The aforementioned trends in the apparent resistivity (fig. 4A) suggest that the resistivity of the ground initially increases with depth and subsequently decreases. These changes are manifested in the estimated model (fig. 4B): The top, middle, and bottom layers have estimated resistivities of 50, 220, and 33 ohm-m, respectively. The calculated apparent resistivities for this model had the best match to the measured apparent resistivities, so this model is termed "most-likely." There are suitable alternative models for which the match between the calculated and the measured apparent resistivities is almost as good as the match for most-likely model; these models are determined by using a procedure called "equivalence analysis." These alternative models have the same trend in resistivity: The resistivites of the top, middle, and bottom layers are always low, high, and low, respectively. For these alternative models, the thickness of the top layer ranges from 11 to $19 \mathrm{~m}$, and the thickness of the middle layer ranges from 79 to $107 \mathrm{~m}$. 

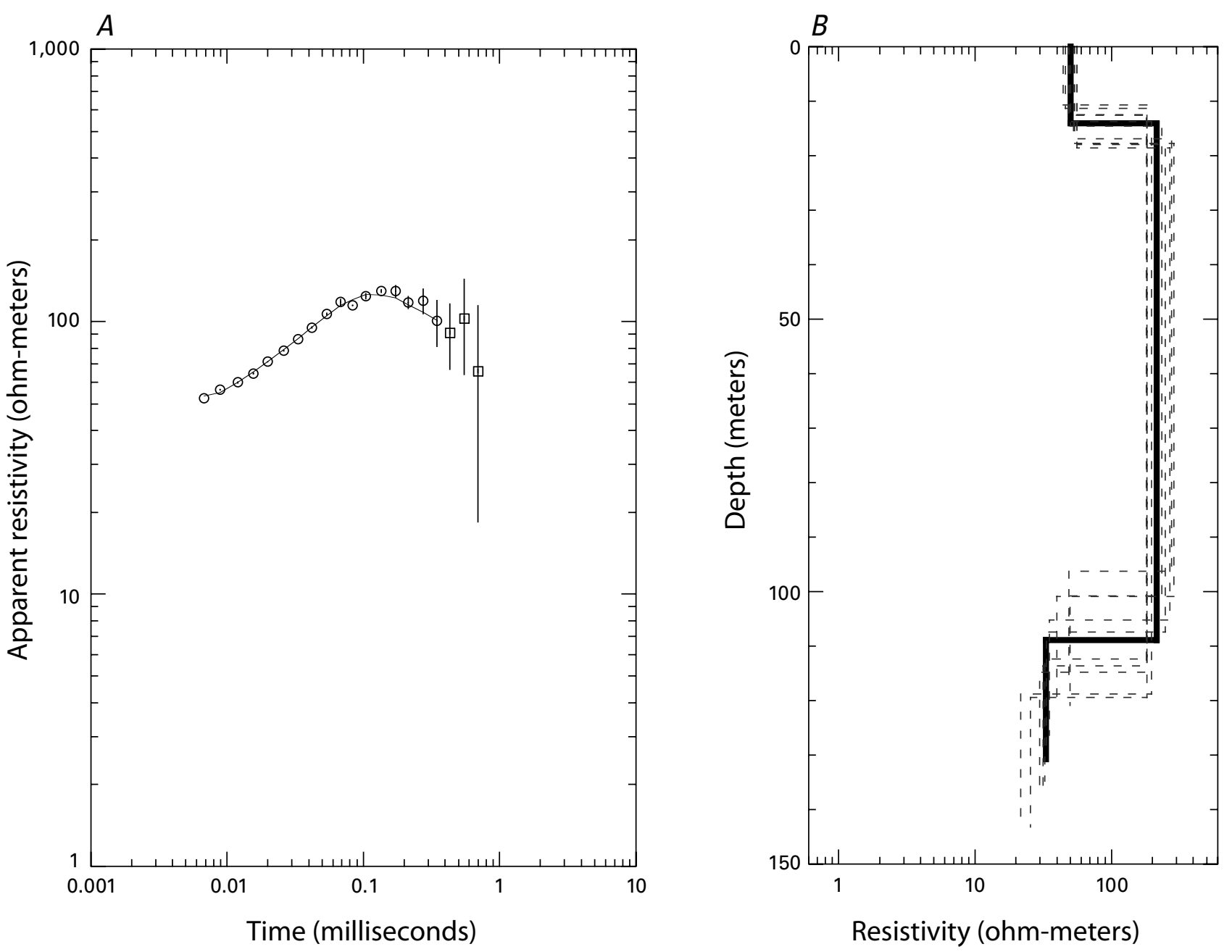

Figure 4. Typical results from a TEM sounding (Sounding 20, pl. 1). A, Apparent resistivities and their standard deviations. Circles represent measured apparent resistivities that were used in the inversion; squares represent measured apparent resistivities that were not used in the inversion; vertical lines represent standard deviations of the apparent resistivities; and the solid, curved line represents the calculated apparent resistivity for the most-likely electromagnetic model. $B$, Electromagnetic model estimated from the apparent resistivities. The heavy, solid line represents the most-likely model; the dashed lines represent suitable, alternative models.

\section{Electrical Resistivity Profiling}

\section{Description of the Method}

Electrical resistivity is a property that indicates how much a material opposes the flow of electrical current. The resistivity of rock or sediment generally depends upon the electrical resistivities of the constituent minerals, of the air in the pores, and of the water in the pores, as well as the relative abundances of the minerals, air, and water.

To measure the electrical resistivity of the ground, direct electrical current is injected into the ground through a metal stake, which is called an "electrode," and the current is extracted with another electrode (fig. 5A). The voltage is measured between two other electrodes that are collinear with the current electrodes. Various orderings of the four electrodes and the spacings between them are used to probe the ground to different depths. To this end, many electrodes (for example, 16 to
100) are arranged in a straight line, and the spacing between all electrodes is constant (fig. 5B). From this large number of electrodes, a data-collection instrument (fig. $5 C$ ) selects four for a single measurement. This instrument rapidly changes the combination of electrodes so that there are measurements for all orderings and spacings. Additional information about the electrical resistivity method and electrical resistivities of typical geologic materials can be found in Zohdy and others (1974), Reynolds (1997), and Zonge and others (2005).

\section{Data Collection}

Electrical resistivity data were collected using a SuperSting R8 IP system manufactured by Advanced Geosciences, Inc. The data were collected with 100 stainless-steel electrodes. The ordering of the four electrodes involved in a single measurement was an "inverse Schlumberger array," for 

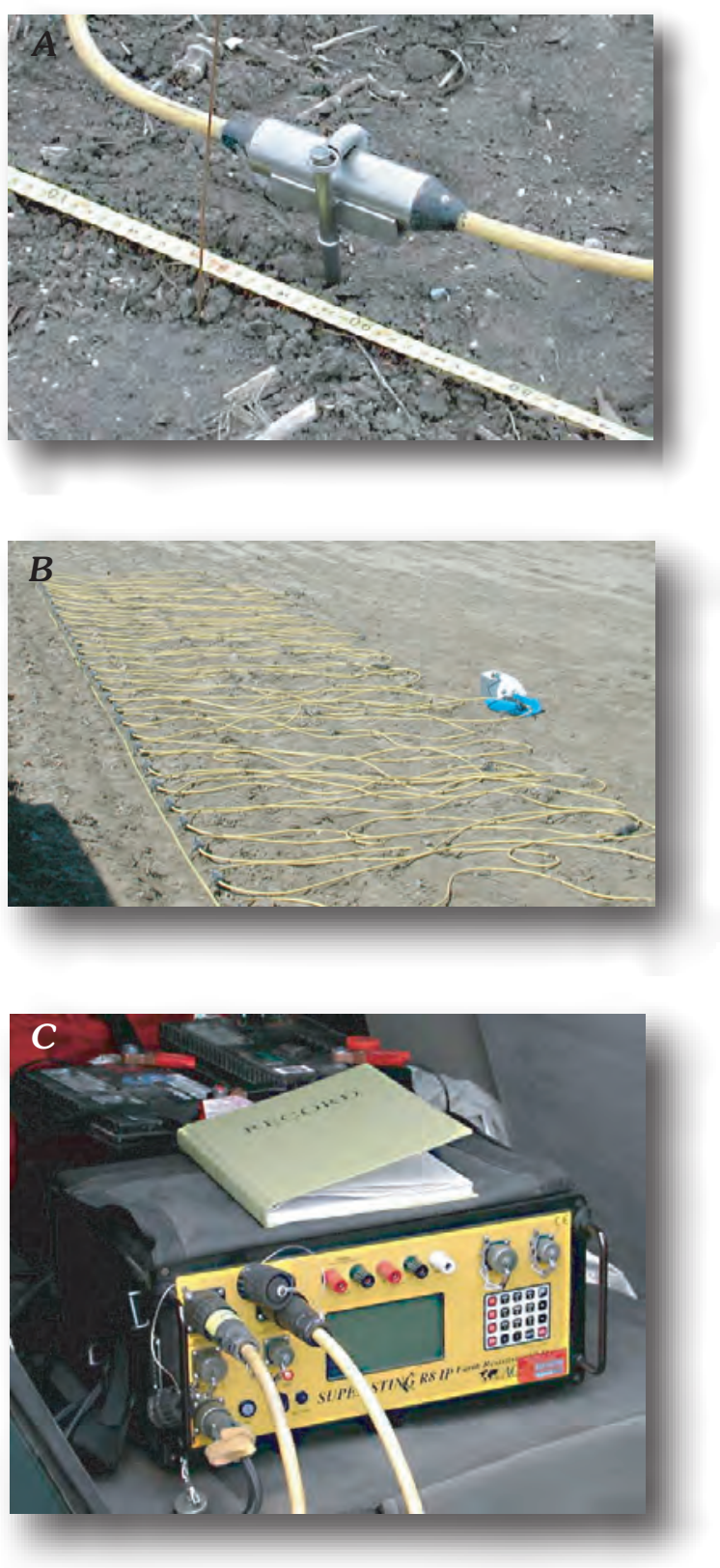

Figure 5. A, Electrode and cable attachment used for electrical resistivity profiling. $B$, Electrodes and the associated cables used to collect one set of measurements. $C$, Instrument used to collect and record the electrical resistivity data.

which the two innermost electrodes were used to inject current into the ground, and the two outermost electrodes were used to measure the voltage. An advantage of the inverse Schlumberger array is that the signal to noise ratio of a measured voltage is often greater than that of other array types. To further improve the signal to noise ratio, each voltage measurement is repeated three times and then averaged.

Electrical resistivity data were acquired along six lines or profiles (pl. 1 and table 1). Two profiles were near the middle of the field and were perpendicular to one another. The remaining four profiles were adjacent to Road 1 . For these four profiles, the spacing of the electrodes varied to determine how spacing affects the delineation of the geologic heterogeneity. All four profiles were centered at the same point. The acquisition parameters for all six profiles are summarized in table 1.

Table 1. Acquisition parameters for the electrical resistivity profiles. The locations of the profiles are shown on plate 1.

\begin{tabular}{lc}
\hline \multicolumn{1}{c}{ Parameter } & Value \\
\hline Electrode spacing (meters) & 4.0 (Profile $B B^{\prime}$ ) \\
& 4.0 (Profile $E E^{\prime}$ ) \\
& 3.0 (Profile $H H^{\prime}$ ) \\
& 2.0 (Profile $\left.I I^{\prime}\right)$ \\
& 1.0 (Profile $J J^{\prime}$ ) \\
& 0.5 (Profile $K K^{\prime}$ ) \\
Profile length (meters) & 297.0 (Profile $B B^{\prime}$ ) \\
& 198 (Profile $E E^{\prime}$ ) \\
& 99.0 (Profile $\left.H H^{\prime}\right)$ \\
& 49.5 (Profile $\left.I I^{\prime}\right)$ \\
& 396 (Profile $\left.J J^{\prime}\right)$ \\
Measurement time (milliseconds) & 396 (Profile $K K^{\prime}$ ) \\
Maximum input current & 1,200 \\
(milliAmperes) & 1,000 \\
\hline
\end{tabular}

\section{Data Processing}

The measurements of voltage were used to estimate the electrical resistivity with an inversion; the software that performed the inversion was chosen to be EarthImager 2D (Advanced Geosciences, Inc., 2003). The inversion is based on a model that is similar to a geologic cross section except that it displays electrical resistivity. The electrical resistivity may vary within the vertical plane of the model, but not perpendicular to this plane. For the inversion, voltages and currents are combined into a single parameter called "apparent resistivity" (Zohdy and others, 1974); the apparent resistivities calculated from the field measurements and from the model are matched during the inversion by varying the electrical resistivities within the model.

\section{Typical Results}

A typical cross section of electrical resistivity is shown in figure 6 . The vertical axis indicates the elevation, and the horizontal axis indicates the horizontal distance along the ground. The cross section represents a vertical slice through the ground, beneath the line of electrodes. The top of the cross section corresponds to the ground surface. The shape of the cross section is trapezoidal. Only this trapezoidal region was thoroughly probed with electrical current; other regions that were partially probed are not shown. The colors in the cross section indicate the estimated electrical resistivity: the red and orange colors indicate high resistivity; the purple and blue colors indicate low resistivity. 


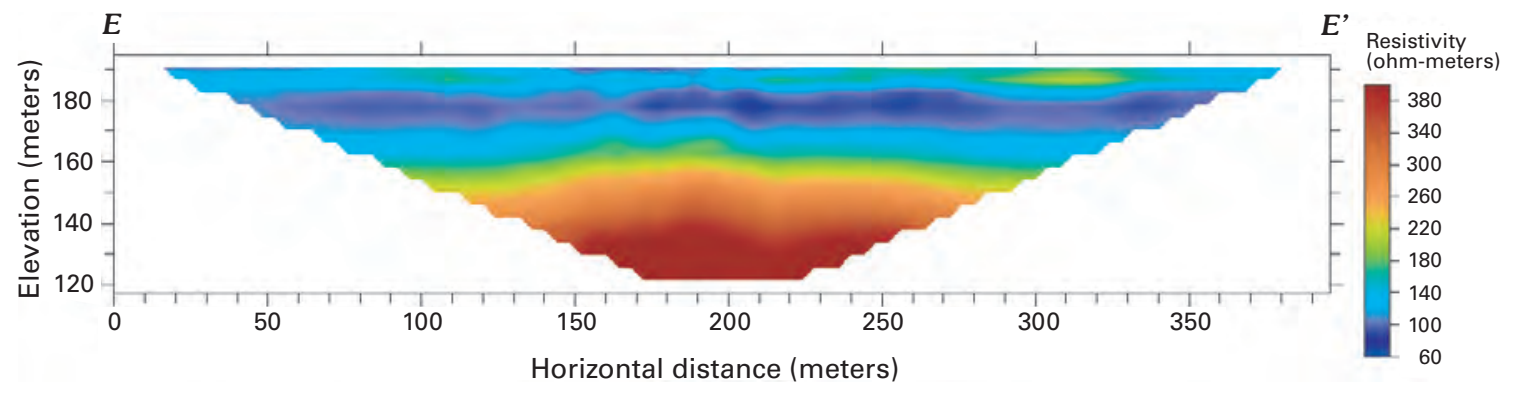

Figure 6. Typical results from an electrical resistivity profile (profile $E E^{\prime}$ on pl. 1).

\section{$S$-wave Reflection Profiling}

\section{Description of the Method}

$S$-wave reflection profiling uses $S$-waves, which are also called "shear waves," to delineate geologic heterogeneity in the ground. The $S$-waves are generated by specially designed sources. One source is a wooden platform with metal plates on either side (fig. 7A). One of the metal plates is struck with a small sledgehammer, and the force impulse is transmitted into the ground, generating an $S$-wave. This source is called the "clog," and it is similar to a source used by the Canadian Geological Survey. Another source is a heavy, metal box with spikes on its bottom that mechanically couple the box to the ground (fig. $7 B$ ). The side of the box is struck with a large sledgehammer, generating an $S$-wave. This source is called the "golf shoe" (Hasbrouck, 1983).

After the $S$-waves are generated by the source, they propagate downward, reflect from interfaces such as the alluvium/bedrock interface, then propagate upward. At the ground surface, the reflected waves are detected by geophones, each of which generates a time-varying voltage that is digitally recorded (fig. $7 C$ and $D$ ). The recorded voltage from each geophone is called a "trace," and it contains fluctuations in the voltage that correspond to reflected waves, as well as other, unwanted waves and background noise. Using various computer algorithms, the unwanted waves and noise are removed from the traces, effectively leaving the reflections. These reflections are subsequently manipulated to generate an image, which is somewhat similar to a geologic cross section. This cross section is markedly improved if the subsurface interfaces have been thoroughly probed with the $S$-waves. To achieve this, traces must be recorded for many different locations of the source and the geophones. Additional information about seismic reflection profiling is in Pelton (2005).

Figure 7. Equipment used for $S$-wave seismic reflection and refraction profiling. $A$, Clog source. $B$, Golf shoe source. The arrows indicate where the golf shoe is struck by a sledgehammer to generate an $S$-wave. $C$, Geophone used to detect the $S$-wave. $D$, Seismograph used to record the time-varying voltages generated by the geophones.

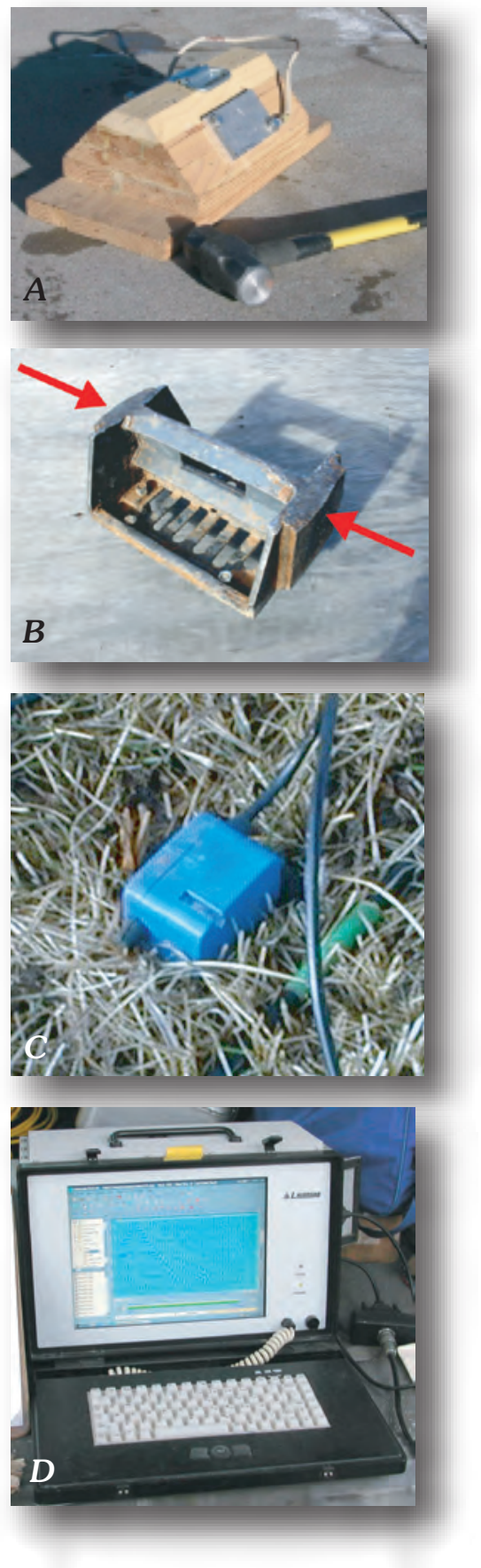


Table 2. Acquisition parameters for the $S$-wave seismic reflection and refraction profiling. The locations of the profiles are shown on plate 1.

\begin{tabular}{lccc}
\hline \multicolumn{1}{c}{ Parameter } & Profile $\boldsymbol{A A}^{\prime}$ & Profile $\boldsymbol{C C}^{\prime}$ & Profile $^{\prime} \mathbf{G G}^{\prime}$ \\
\hline Number of geophones & 48 & 96 & 48 \\
Geophone spacing (meters) & 2.5 & 4.0 & 2.5 \\
Natural frequency of geophone (Hertz) & 10 & 10.0 & 10 \\
Component of particle velocity detected by geophone & horizontal & horizontal & horizontal \\
& (perpendicular & (perpendicular & (perpendicular \\
& to seismic line) & 24 & to seismic line) \\
Number of shot positions & 49 & 24.0 & 49 \\
Shot spacing (meters) & 2.5 & golf shoe & 2.5 \\
Source type & clog & 9.1 & clog \\
Sledgehammer weight (kilograms) & 1.8 & 0.6 & 3.6 \\
Duration of traces (seconds) & 0.8 & 0.5 & 0.8 \\
Sample interval (milliseconds) & 0.5 & & 0.5 \\
\hline
\end{tabular}

\section{Data Collection}

Data were collected along profiles $A A^{\prime}, C C^{\prime}$, and $G G^{\prime}$ (pl. 1); the acquisition parameters for each profile are summarized in table 2. Profile $A A^{\prime}$ was parallel to Road B, and the clog source was placed on the road to minimize the surface wave, which is a type of unwanted wave. The source and geophone spacing were small so that alluvium/bedrock interface, which reflected the $S$-waves, was thoroughly probed. Profile $G G^{\prime}$ was in the farm field, and its acquisition parameters were identical to those for profile $A A^{\prime}$, except that a heavier sledgehammer was used. Profile $C C^{\prime}$ was also in the farm field and was collinear with profile $G G^{\prime}$. The acquisition parameters for profile $C C^{\prime}$ were chosen to give the best head waves, which are needed for refraction profiling (see the section " $S$-wave Refraction Profiling"). The reason was that profile $G G^{\prime}$ ' was originally intended to be a refraction profile, not a reflection profile. However, when the traces were later analyzed, it was discovered that they also recorded reflected waves. Consequently, profile $G G^{\prime}$ was also analyzed as a reflection profile. Analyses of the seismic cross sections for these two profiles indicate how they are affected by different acquisition parameters.

An example of some $S$-wave reflection data from profile $G G^{\prime}$ is shown in figure 8 . Each trace is plotted at the horizontal distance of the associated geophone. The waves that are pertinent to this study are highlighted. The direct wave propagates directly from the source to the geophones, through the alluvium. The reflected wave reflects from the interface between the alluvium and the bedrock; such waves are used to generate the reflection image. The head wave is described in the section "S-wave Refraction Profiling."

\section{Data Processing}

The procedures used to process the reflection data are summarized in table 3, and information about these procedures is in Yilmaz (1987). The purpose of this processing is to convert the traces into something similar to a geologic cross

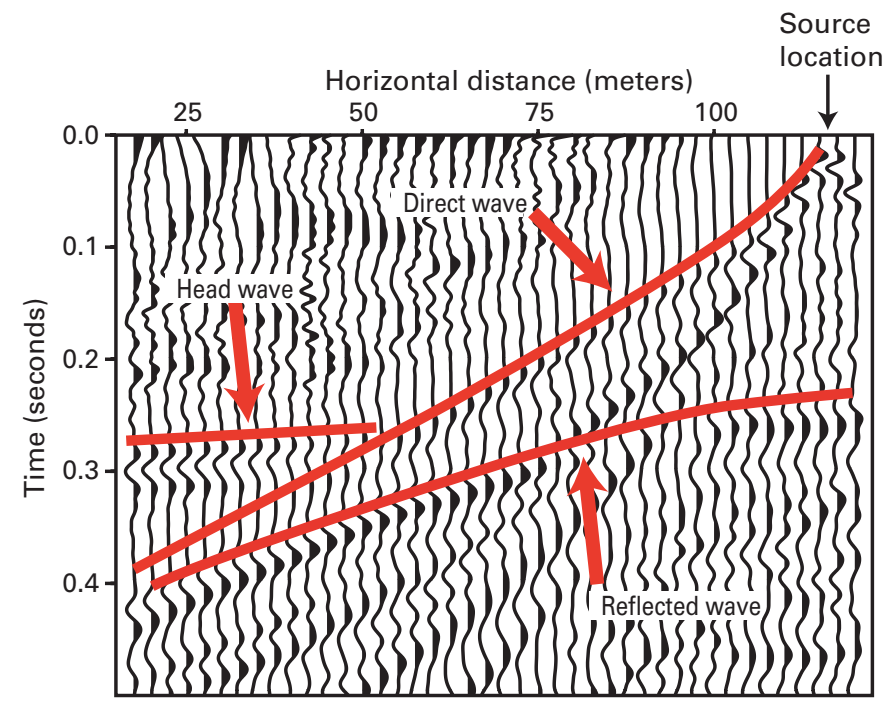

Figure 8. S-wave seismic reflection and refraction data recorded in the farm field (profile $G G^{\prime}$ on pl. 1).

Table 3. Procedures used to process the $S$-wave reflection data.

\begin{tabular}{cc}
\hline \multicolumn{1}{c}{ Procedure } & Purpose \\
$\begin{array}{c}\text { Stacking of common } \\
\text { source gathers }\end{array}$ & $\begin{array}{c}\text { Check the shot quality, remove } P \text {-waves } \\
\text { and other noise }\end{array}$ \\
$\begin{array}{c}\text { Sorting of traces to } \\
\text { produce common } \\
\text { midpoint gathers }\end{array}$ & $\begin{array}{c}\text { position reflection points beneath geo- } \\
\text { phones }\end{array}$ \\
$\begin{array}{c}\text { Frequency-wavenumber } \\
\text { (f-k) filtering }\end{array}$ & Remove noise \\
$\begin{array}{c}\text { Surgical muting } \\
\text { Normal moveout cor- } \\
\text { rection }\end{array}$ & $\begin{array}{c}\text { Remove refracted waves } \\
\text { Flatten reflected arrivals }\end{array}$ \\
$\begin{array}{c}\text { Stacking of common } \\
\text { midpoint gathers }\end{array}$ & $\begin{array}{c}\text { Convert each common midpoint gather } \\
\text { into a single trace for image }\end{array}$ \\
Frequency filtering & Remove noise \\
Automatic Gain Control & Balance amplitudes of weaker (later) \\
& reflections \\
Frequency-offset (f-x) & Enhance lateral coherency, minimize \\
deconvolution & spurious energy
\end{tabular}


section, which can be readily understood and interpreted. The cross section is often called a "reflection image," and its accuracy depends upon the properties of the $S$-waves, the properties of the geology, and the quality of the processing.

\section{Typical Results}

The reflection image along profile $A A^{\prime}$ is shown in figure 9. The vertical axis indicates depth; the horizontal axis indicates the horizontal distance along the ground. The positive and negative values in the image are represented by red and blue colors, respectively. The prominent horizontal line at about 33-m depth corresponds to a wave reflected from a horizontal interface. Such coherent features in the cross section correspond to geologic features such as interfaces.

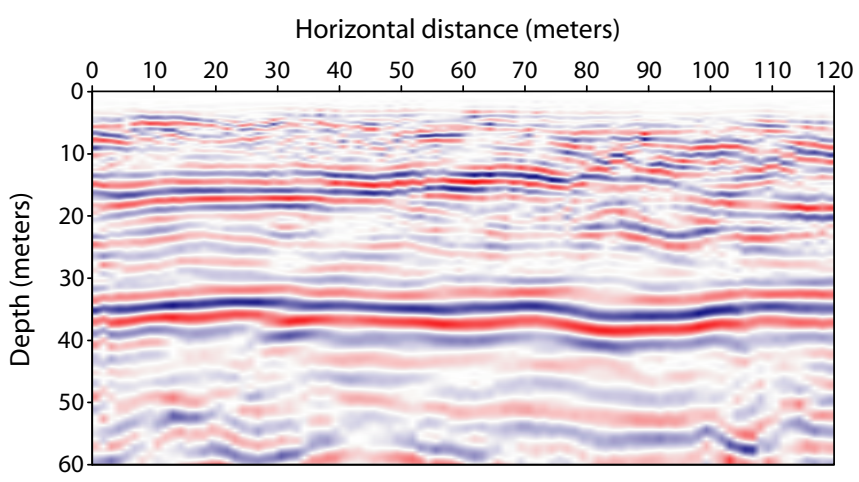

Figure 9. Typical results from an $S$-wave reflection profile (profile $A A^{\prime}$ on pl. 1).

\section{$S$-wave Refraction Profiling}

\section{Description of the Method}

$S$-wave refraction profiling, like reflection profiling, uses $S$-waves to delineate geologic heterogeneity in the ground. Indeed, the sources and the geophones used for reflection profiling are also used for refraction profiling (fig. 7). Despite the usage of the same equipment, the methods are different. To understand this, consider an $S$-wave propagating through the ground and then impinging on an interface, say the interface between alluvium and bedrock. A portion of the $S$-wave is reflected from the interface - this reflected wave is used in reflection profiling. The remaining portion of the $S$-wave is transmitted through the interface - this transmitted wave is used in refraction profiling. Because of changes in the $S$-wave velocity, the transmitted wave is bent or refracted, just as light is refracted as it passes from air to glass. This transmitted wave in the bedrock is subsequently refracted again into the alluvium, and it propagates to the ground surface where it is detected by geophones. This twice-refracted wave is called a "head wave," and an example of a head wave is shown in figure 8 .
The goal of processing the $S$-wave refraction data is the same as that of processing the $S$-wave reflection data - to generate a seismic cross section that can be readily related to the geology. However, because the nature of head waves differs significantly from that of reflected waves, the processing differs significantly. The details of the processing are described in the subsection "Data Processing."

$S$-wave refraction profiling is somewhat new compared to other geophysical methods, so only a few publications describing this method are available (Ellefsen and others, 2005).

Because $S$-wave and $P$-wave refraction profiling are somewhat similar, the references listed in the section on $P$-wave refraction profiling may be helpful.

\section{Data Collection}

Originally, profile $C C^{\prime}$ was intended to be an $S$-wave refraction profile, and profiles $A A^{\prime}$ and $G G^{\prime}$ were intended to be $S$-wave reflection profiles. However, when the data from profiles $A A^{\prime}$ and $G G^{\prime}$ were analyzed, head waves were observed, so the data from these two profiles were also processed as $S$-wave refraction profiles. The data collection for all three profiles is described in the section " $S$-wave Reflection Profiling," and the parameters used to collect the data are listed in table 2.

\section{Data Processing}

The processing consists of three steps. First, the traces are stacked to improve the signal to noise ratio. Second, the times at which the direct and the head waves arrive at the geophones are measured; these measured times are often called "traveltimes." Figure $10 \mathrm{~A}$ shows an example of the traveltimes along profile $G G^{\prime}$. The horizontal axis refers to the horizontal distance along the seismic profile, and the vertical axis refers to the traveltime. The colors indicate the confidence in the accuracy of the traveltime, which can be high, moderate, or low. The third step in the processing is to generate a seismic cross section from the measured traveltimes. To this end, a seismic cross section is proposed, and to each part of the cross section an $S$-wave velocity is assigned. Traveltimes for this proposed section are calculated and then compared to the measured traveltimes. The differences between these calculated and measured traveltimes indicate how the cross section should be revised. This procedure is called "traveltime inversion" and is a type of optimization.

\section{Typical Results}

The seismic cross section for profile $G G^{\prime}$ is shown in figure $10 \mathrm{~B}$. The vertical axis indicates the elevation, and the horizontal axis indicates the horizontal distance along profile $G G^{\prime}$. The top of the cross section corresponds to the ground surface, and the other sides indicate the region probed by the $S$-waves. The cross section appears blocky because the 
traveltime inversion uses blocks to represent the ground. The cross section has three layers: In the top layer, the $S$-wave velocity is less than $150 \mathrm{~m} / \mathrm{s}$; in the middle layer, the $S$-wave velocity ranges from about 150 to $450 \mathrm{~m} / \mathrm{s}$; and in the bottom layer, $S$-wave velocity is greater than $2,140 \mathrm{~m} / \mathrm{s}$.

The reliability of the seismic cross section may be qualitatively assessed in at least two different ways. First, the calculated traveltimes for the cross section should be compared to measured traveltimes (fig. 10A). For this cross section, the measured and calculated traveltimes are similar, indicating that the cross section may be reliable. Second, the number of rays passing through each block should be checked (fig. 10C). Where the number is low, the estimated velocity is unreliable; in contrast, where the number is high, the estimated velocity may be reliable. For example, near 250-m horizontal distance and $170-\mathrm{m}$ elevation, no rays passed through the blocks, so the estimated velocity is unreliable. On the other hand, near 300-m horizontal distance and 158-m elevation, more than 32 rays passed through the blocks, so the estimated velocity may be reliable. Notice that no rays pass through the blocks along the perimeter of figure $10 C$; these blocks are omitted from the cross section in figure $10 \mathrm{~B}$.
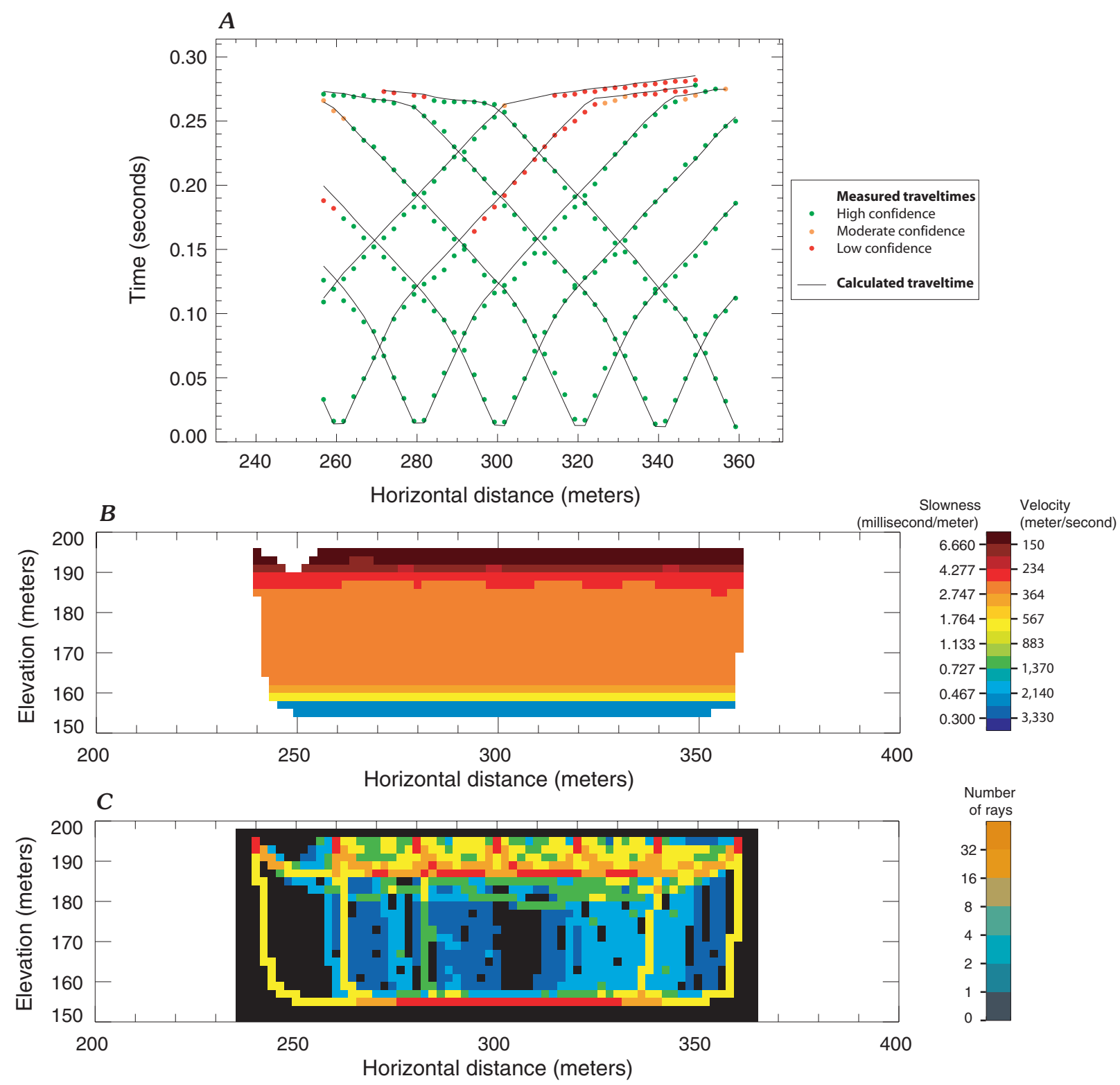

Figure 10. Typical results from an $S$-wave refraction profile (profile $G G^{\prime}$ on pl. 1). $A$, Measured and calculated traveltimes. $B$, Cross section showing the $S$-wave velocities estimated from the measured traveltimes. $C$, Cross section showing the number of rays passing through each block in the seismic cross section. $\mathrm{M}$, millisecond; m, meters; $\mathrm{s}$, second. 


\section{$P$-wave Refraction Profiling}

\section{Description of the Method}

$P$-wave refraction profiling uses direct $P$-waves and head $P$-waves to delineate geologic heterogeneity in the ground. The direct and head $P$-waves are somewhat similar to direct and head $S$-waves, so $P$-wave refraction profiling is somewhat similar to $S$-wave refraction profiling. Nonetheless, the $P$ - and $S$-waves have different properties, and two differences are especially important here: The velocity of $P$-waves is always higher then the velocity of $S$-waves, and $P$-waves are strongly affected by the fluids in the pores, whereas $S$-waves are practically unaffected.

For the refraction profiling, $P$-waves were generated with two different types of sources. The first source was mounted on a modified drilling truck (fig. 11A), and the principal parts of the source consisted of a metal bar and a metal plate (fig. 11B). The metal bar, which weighed over $100 \mathrm{~kg}$, was lifted about $2 \mathrm{~m}$ off the ground and then released. It hit the metal plate, which was firmly implanted in the ground, and this impact generated $P$-waves. This source is called the "truck-mounted, weight-drop source." The second source consisted of a sledgehammer and a metal plate (fig. 11C). This source generated $P$-waves when the metal plate was struck by the sledgehammer, which weighed about $9.1 \mathrm{~kg}$. This source is called the " $9.1-\mathrm{kg}$ sledgehammer source." The $P$-waves generated by both sources were detected by geophones that were especially suitable for $P$-wave refraction profiling (fig. 11D). These geophones differ from those used for the $S$-wave reflection and refraction profiling because of the inherent differences in the waves. The time-varying voltages generated by the geophones are digitized and recorded by the seismograph (fig. 7D). Additional information about this method may be found in Dobrin and Savit (1988), Telford and others (1990), Reynolds (1997), and Pelton (2005).
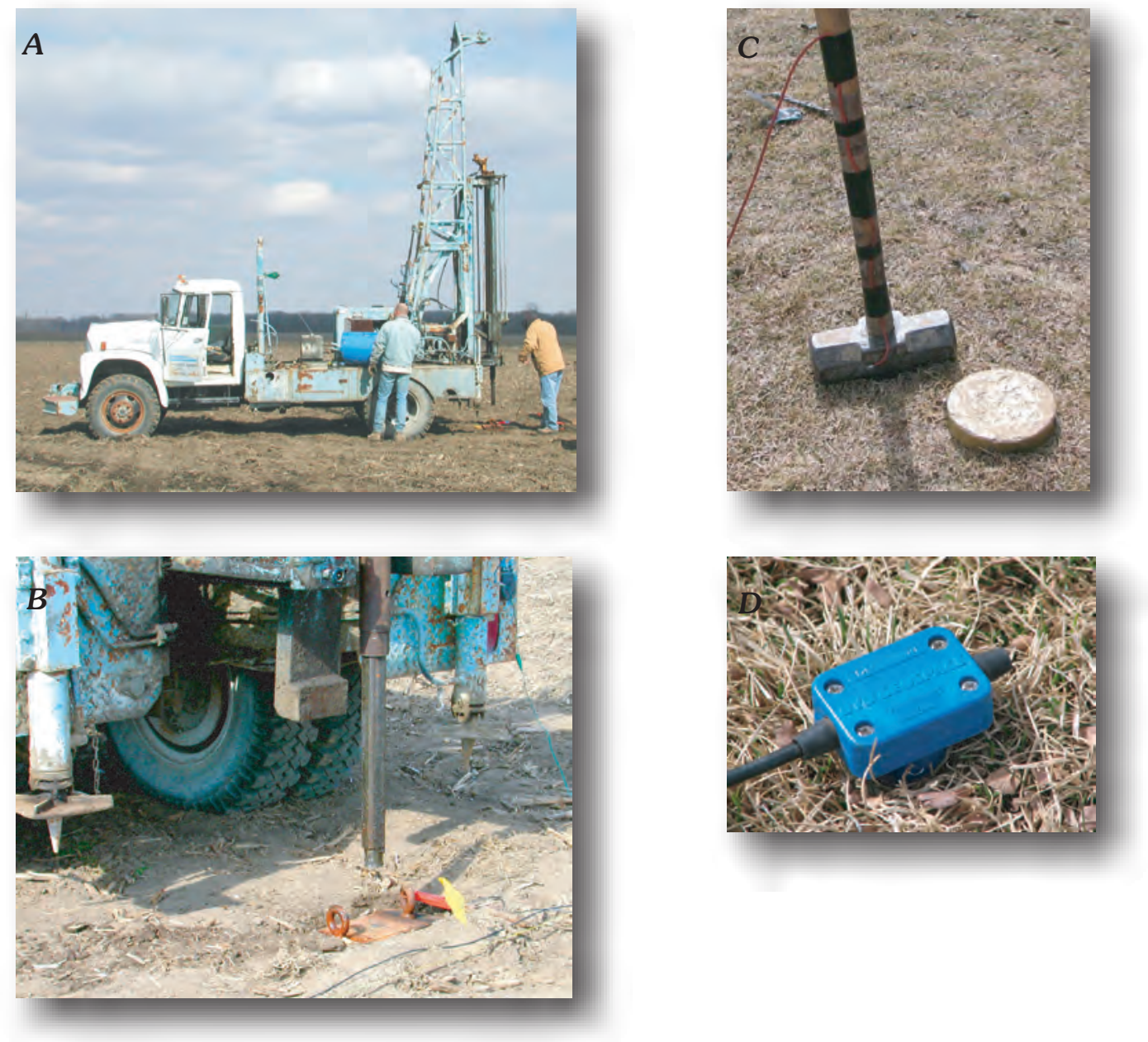

Figure 11. Equipment used for $P$-wave refraction profiling. $A$, Truck-mounted, weight-drop source. $B$, Close-up view of the truckmounted, weight-drop source. $C$, 9.1-kilogram sledgehammer source. $D$, Geophone used to detect $P$-waves. 


\section{Data Collection}

Data were collected along profiles $D D^{\prime}$ and $F F^{\prime}$ (pl. 1); the acquisition parameters for each profile are summarized in table 4. Both profiles were in the farm field and were collinear. There was one significant difference between the two profiles: the source for profile $D D^{\prime}$ was the 9.1-kg sledgehammer, whereas the source for profile $F F^{\prime}$ was the truck-mounted weight-drop. The reason for the two different sources was to evaluate how well each type could generate data for refraction profiling.

Table 4. Acquisition parameters for the $P$-wave refraction profiling. The locations of the lines are shown on plate 1.

\begin{tabular}{lcc}
\hline \multicolumn{1}{c}{ Parameter } & Profile $\boldsymbol{D D}^{\prime}$ & Profile $\boldsymbol{F F}^{\prime}$ \\
\hline $\begin{array}{l}\text { Number of geophones } \\
\text { Geophone spacing }\end{array}$ & 96 & 48 \\
$\quad$ (meters) & 4.0 & 4.0 \\
$\quad \begin{array}{l}\text { Natural frequency of } \\
\text { geophone (Hertz) }\end{array}$ & 10 & 10 \\
Component of particle & vertical & vertical \\
$\quad$ velocity detected by & & \\
$\quad$ geophone & 24 & 11 \\
Number of shot positions & 24 & 24 \\
Shot spacing (meters) & $9.1-\mathrm{kg}$ & Truck-mounted, \\
Source type & sledgehammer & weight-drop \\
$\quad$ Duration of traces (sec- & 0.6 & 0.8 \\
$\quad$ onds) & & 0.5 \\
Sample interval (millisec- & 0.5 & \\
$\quad$ onds) & & \\
\hline
\end{tabular}

Some $P$-wave refraction data from profile $F F^{\prime}$ are shown in figure 12. There are three waves that are pertinent to the $P$-wave refraction profiling: the direct wave, which propagates directly from the source to the geophones; the head wave from the water table (namely, the interface between the unsaturated and saturated zones); and the head wave from the interface between the alluvium and the bedrock.

\section{Data Processing}

The processing of $P$-wave refraction data is practically identical to that for $S$-wave refraction data, so information about processing may be obtained from the section " $S$-wave Refraction Profiling."

\section{Typical Results}

The seismic cross sections obtained with $P$-wave refraction profiling are generally identical to those obtained with the $S$-wave refraction profiling. The only significant difference is that the $P$-wave cross sections show the $P$-wave velocity, whereas the $S$-wave cross sections show the $S$-wave velocity. Information about the cross sections, as well as the plots of traveltimes and ray density, may be obtained from the section "S-wave Refraction Profiling."

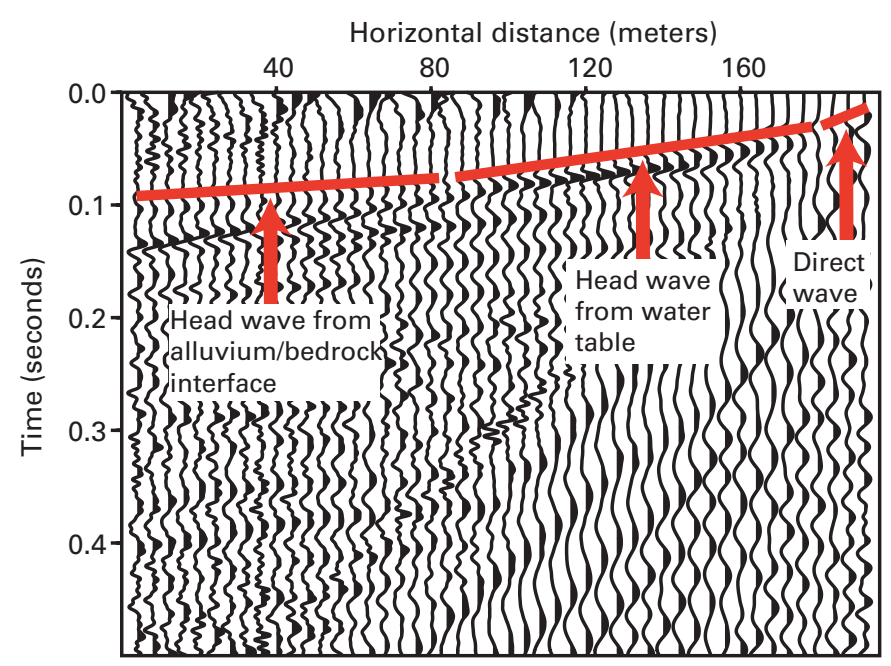

Figure 12. $P$-wave refraction data recorded in the farm field (profile FF' on pl. 1).

\section{Interpretation}

\section{Time-Domain Electromagnetic Soundings}

The TEM soundings were interpreted with the simplest models that could fit the observations. In general, this could be accomplished with three-layer models in which the top layer had intermediate resistivities (50 to $90 \mathrm{ohm}-\mathrm{m}$ ), the middle layer had moderately high resistivities (200 to $1,500 \mathrm{ohm}-\mathrm{m}$ ), and the bottom layer had low resistivities (10 to $50 \mathrm{ohm}-\mathrm{m}$ ). Depths to the interface between the top and the middle layers ranged from 13 to $41 \mathrm{~m}$, and the depths to the interface between the middle and the bottom layers ranged from 74 to $110 \mathrm{~m}$. For some of the interpretations, the first layer was subdivided into two or three layers to determine whether such a subdivision might improve the match between the observed and the calculated data and also improve the agreement between the TEM models and the driller's logs. However, neither of these two improvements occurred.

Figure 13 shows examples of two interpretations, including the driller's logs near the soundings. In the model for sounding 13 (fig. 13A), the interface between the top and the middle layers is at a depth of $22 \mathrm{~m}$, which corresponds to the clay layer in the driller's log. At this depth, the resistivity increases from 64 to $680 \mathrm{ohm}-\mathrm{m}$, but what is expected is that the resistivity should decrease because of the clay layer. On the other hand, if the clay layer were merely one or two meters thick, then its influence on the sounding would be insignificant, and the layer would probably be undetectable. Unfortunately, the driller's log does not provide any information on the thickness of the clay layer.

In the model for sounding 27 (fig. 13B), the interface between the top and the middle layers is at a depth of $41 \mathrm{~m}$, which is significantly below the bottom of the driller's log. This depth is within the Devonian limestone and dolomite (fig. 1). It is possible that the upper portion of this bedrock is weathered and fractured, reducing its electrical resistivity. 
In this case, the top layer would include the soil, alluvium, and the upper portion of the bedrock. However, such a thick top layer would be expected in all TEM models for the site, but it appears in only a few.

The generalized stratigraphic column (fig. 1) indicates that the depth to the bedrock ranges from $16 \mathrm{~m}$ to more than $32 \mathrm{~m}$; this range is somewhat similar to the range for the interface between the top and the middle layers in the TEM models (namely, 13 to $41 \mathrm{~m}$ ). Thus, the top layer in all TEM models roughly corresponds to the combined soil and alluvium. Likewise, the stratigraphic column indicates that the top of the Ordovician shale and shaley limestone could be as deep as 85 to $106 \mathrm{~m}$; this range corresponds well to the range for the interface between the middle and bottom layers in the TEM models (namely, 74 to $110 \mathrm{~m}$ ). Thus, the bottom layer in all TEM models corresponds to the shale and shaley limestone. By inference, the middle layer in the TEM models must correspond to a composite of the Devonian limestone and
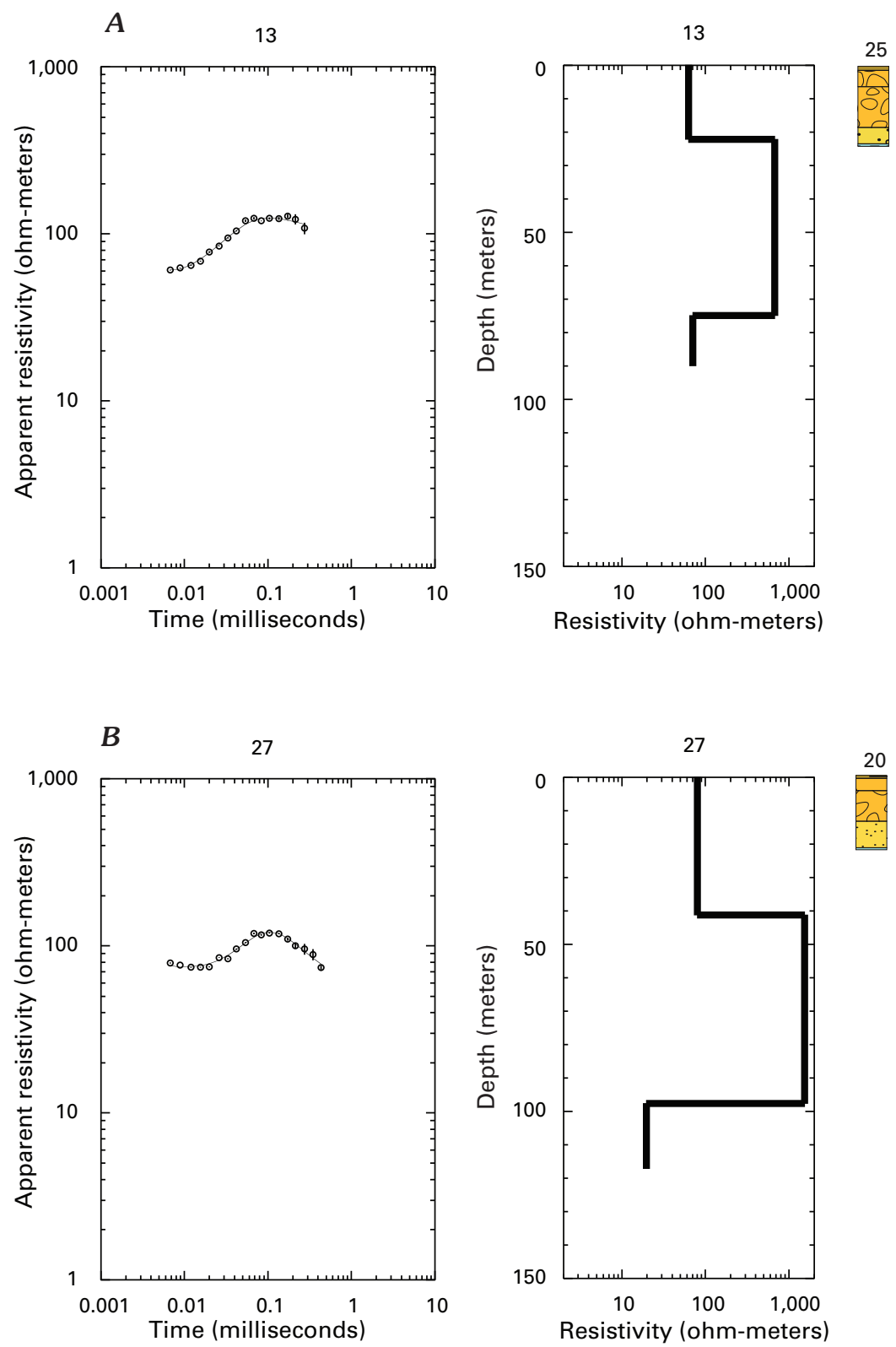

Figure 13. $A$ and $B$, Interpretations of two time-domain electromagnetic soundings, including the driller's logs from the holes that are closest to the soundings. The sounding number, which is at the top of each graph of apparent resistivity, may be used to locate the sounding within the site (pl. 1). Likewise, the drill-hole number, which is at the top of each driller's log, may be used to locate the drill hole within the site (pl. 1). Explanation of the symbols that are used in the graphs are in the caption for figure 4. Explanations of the symbols that are used in the driller's logs are on plate 2. 
dolomite and the underlying Silurian limestone and dolomite. A general correspondence exists, therefore, between the generalized stratigraphic section and the three-layer TEM models (fig. 1).

The TEM soundings did not delineate the stratigraphy as well as expected. The reason for these modest results is probably the shallow target - the soil, gravel, and sand layers in the first 14 to $41 \mathrm{~m}$ of depth. To obtain information about these layers, the transient would have to be sampled at times earlier than 6.9 microseconds, and such sampling cannot be done with any commercially available equipment. Also, the contrast between the high resistivities of the gravel and the sand may be too small to be detected by the TEM soundings. Despite the modest results, the TEM soundings did estimate the depth to the shale and shaley limestone.

\section{Electrical Resistivity Profiles}

For profile $B B^{\prime}$ (pl. 3), the cross section of electrical resistivity is interpreted in terms of three layers, which are displayed in the geologic cross section. The bottom layer extends from 122-m elevation, where the resistivity is greater than $380 \mathrm{ohm}-\mathrm{m}$, to $160-\mathrm{m}$ elevation, where the resistivity is about $220 \mathrm{ohm}-\mathrm{m}$. The driller's logs for holes 57 and 61 do not record the bedrock; hence, the top of the bedrock must be below about 164-m elevation. This bedrock is the Devonian limestone and dolomite (fig. 1), and rocks of these types have measured electrical resistivities that range approximately from 50 to $10^{7} \mathrm{ohm}-\mathrm{m}$ (Telford and others, 1990, p. 290; Reynolds, 1997, p. 422). Consequently, the bottom layer is interpreted as the Devonian limestone and dolomite. Within this layer, the resistivity decreases as the elevation increases, perhaps because fracturing and weathering increase. Near the top of this layer, which is at about 160-m elevation, the resistivity varies slightly with horizontal distance. This variation probably is not due to the geology but rather is due to noise in the data or distortion inherent in the processing.

The middle layer extends approximately from 160- to 193-m elevation. Interpretation of this layer is somewhat difficult because its resistivity varies considerably in both the horizontal and the vertical directions. Nonetheless, there is a general trend in the vertical direction: the resistivity decreases from $220 \mathrm{ohm}-\mathrm{m}$ at $160-\mathrm{m}$ elevation to about $80 \mathrm{ohm}-\mathrm{m}$ at 180-m elevation and increases thereafter. At drill holes 57 and 61 and between the elevations of about 164 and $193 \mathrm{~m}$, this layer consists of sand, fine gravel and sand, and coarse gravel and sand. Clays, sands, and gravels have measured electrical resistivities that range from 1 to $800 \mathrm{ohm}-\mathrm{m}$ (Reynolds, 1997, p. 422). Consequently, the middle layer is interpreted as a composite of the clay, the sand, the fine gravel and sand, and the coarse gravel and sand.

The top layer extends approximately from 193- to 194-m elevation, which is the surface of the ground. The ground surface was covered with soil, and the driller's $\operatorname{logs}$ for holes 57 and 61 indicate soil at approximately the aforementioned elevations. Consequently, the top layer is interpreted as soil.

The measurements of the depth to the water table indicate that almost all of the alluvium is saturated (pl. 2). This saturated alluvium probably has low electrical resistivity because the pore water has low resistivity due to dissolved salts and nitrates from fertilizer. In contrast, the unsaturated alluvium and soil probably have a somewhat higher resistivity, simply because they lack pore water. Despite this hypothesized significant contrast in resistivity, the cross section of electrical resistivity does not show separate layers for the saturated and the unsaturated zones (pl. 3). The reason is that the electrode spacing is $4.0 \mathrm{~m}$ (table 1), which is too large to detect the thin, unsaturated zone.

Although clays usually have significantly lower resistivities than sands and gravels (Reynolds, 1997, p. 422), the cross section of electrical resistivity does not have a separate layer for the clay that is at the bottom of the alluvium (fig. 1 and pl. 3) because this clay is too thin and too deep to be detected.

In the middle layer, which represents the alluvium, the lateral changes in resistivity might be caused by lateral changes in the composition of the alluvium because the driller's logs indicate different compositions in holes 57 and 61. Alternatively, the lateral changes might be caused by changes in the electrical resistivity of the ground water, which in turn might be caused by changes in the concentration of dissolved salts and nitrates. Selecting the more likely of these two interpretations, or even another interpretation, is inappropriate without additional information such as geophysical well logs.

The cross section of electrical resistivity in profile $E E^{\prime}$ appears similar to that in profile $B B^{\prime}$ (pl. 3); indeed, where the profiles intersect, the estimated resitivities are practically identical. Consequently, the interpretation of the cross section in profile $E E^{\prime}$ is identical to that in profile $B B^{\prime}$. Likewise, the cross section in profile $H H^{\prime}$ (composite) appears similar to that in profile $B B^{\prime}$; the only significant difference is the elevation of the interface between the middle and the bottom layers: this elevation is about $170 \mathrm{~m}$ in $H H^{\prime}$ (composite) but is at about $160 \mathrm{~m}$ in $B B^{\prime}$. Thus, the interpretation of $H H^{\prime}$ (composite) is similar to that of $B B^{\prime}$, except that the top of the bedrock is at 170-m elevation. This change in the elevation of the bedrock is consistent with the change inferred from the driller's logs (see "Description of the Field Site").

The cross sections of electrical resistivity in $K K^{\prime}, J J^{\prime}$, $I I^{\prime}$, and $H H^{\prime}$ were developed from measurements for which the electrode spacings were $0.5,1.0,2.0$, and $3.0 \mathrm{~m}$, respectively (table 1 and pl. 3). The sizes of these four cross sections increase as the electrode spacing increases, simply because more ground is probed with electric current. To see a subtle change in all four cross sections, examine, for example, the anomaly at the ground surface at 150 -m horizontal distance. The size, the shape, and the resistivity of this anomaly vary from cross section to cross section. Because these three features depend upon the electrode spacing, the interpretation of any anomaly must account for the electrode spacing. Notice that all four cross sections lack variations near their bases. 
Assuming that there are indeed such small anomalies within the ground, the electric resistivity profiling was unable to detect them. Thus, the capability to detect small anomalies is high near the ground surface but decreases with depth, and the interpretation of any anomaly must account for its depth.

\section{$S$-wave Reflection Profiles}

In profile $A A^{\prime}$ (pl. 3), the $S$-wave reflection image is interpreted in terms of four layers, which are shown in the interpreted geologic cross section. The reflection image is dominated by two horizontal events. The lower event, whose top is at about 160-m elevation, has high amplitude and is coherent across the image. The driller's log for hole 69 does not record the bedrock; hence, the top of the bedrock must be below about 164-m elevation. Because the alluvium and the bedrock have very different $S$-wave velocities (see the following section, "S-wave Refraction Profiles"), the interface between them will generate a reflection. Consequently, the horizontal event at about 160-m elevation is interpreted as the interface between the alluvium and the bedrock, which is the Devonian limestone and dolomite.

There is an alternative, more sophisticated interpretation of this horizontal event. During surveys in other areas, reflected $S$-waves are sometimes generated at interfaces between sand and clay layers (Benjumea and others, 2001a; Benjumea and others, 2001b), and so during this survey a reflected wave may also be generated at the interface between the sand and clay layers. However, because the clay layer is merely 1 to $6 \mathrm{~m}$ thick (fig. 1), the reflected wave from the sand/clay interface would be superimposed on the reflected wave from the clay/bedrock interface. For this reason, the horizontal event at about 160-m elevation could be interpreted as a superposition of two reflections. The reflection from the clay/bedrock interface probably has higher amplitude than that from the sand/clay interface because the change in the $S$-wave velocities is greater. We believe that this interpretation is more likely to be correct than the previous interpretation, but we have no information to substantiate this belief.

The upper horizontal event, whose top is at about $180-\mathrm{m}$ elevation, has moderate amplitude and is partially coherent across the reflection image. Because of its elevation, this event must be caused by changes within the alluvium. The driller's $\log$ for hole 69 indicates that, at about 180-m elevation, the sediments change from fine gravel and sand to sand (pl. 3). Consequently, this horizontal event is interpreted as the interface between the layer of fine gravel and sand and the layer of sand.

The top layer in the geologic cross section is soil. Although this layer does not generate any reflection, it is indicated in the driller's log for hole 69 and is observed at the ground surface. Consequently, the soil layer is included in the cross section.

In profile $G G^{\prime}$ (pl. 3), the reflection image is dominated by one horizontal event. This event has the same amplitude, coherence, and elevation that the corresponding event in $A A^{\prime}$ has; consequently, the interpretation is identical. The reflection image for $G G^{\prime}$ lacks the horizontal event at about $180-\mathrm{m}$ elevation, which was observed in the image for $A A^{\prime}$ (pl. 3). Because the geology along the two profiles is practically identical (pl. 2), this difference may seem surprising. However, the data for $A A^{\prime}$ were collected along Road B (pl. 1), where the sediments at the ground surface are highly compacted. This compaction significantly reduces the generation of a wave that propagates along the ground surface (namely, a Love wave). In contrast, the data for $G G^{\prime}$ were collected within the farm field (pl. 1), where the sediments at the ground surface are not compacted. Here, high-amplitude Love waves are generated, and they overlapped reflections from interfaces within the alluvium. Thus, these Love waves obscured these reflections, making them unobservable in the reflection image.

The interpretation of the reflection image for $C C^{\prime}$ is identical to that for $G G^{\prime}$, and consequently the interpretation is not discussed. Instead, consider the general appearance of the two cross sections: The horizontal event at 160-m elevation is partially coherent in $C C^{\prime}$ but is almost completely coherent in $G G^{\prime}$. The background random noise is significant in $C C^{\prime}$ but is practically insignificant in $G G^{\prime}$. The reason for these two differences is the acquisition parameters (table 2). The spacing between the sources and the spacing between the receivers both are much larger for $C C^{\prime}$ than they are for $G G^{\prime}$. Consequently, both the extent to which the ground is probed and the suppression of random noise are much less for $C C^{\prime}$ than they are for $G G^{\prime}$.

\section{$S$-wave Refraction Profiles}

Along $A A^{\prime}$ (pl. 3), the $S$-wave refraction velocities are interpreted with two layers. The top layer is a composite of the top three layers in the geologic cross section; in other words, it is a composite of the fine-grained alluvium, the coarse-grained alluvium, and the soil. The velocities in this top composite layer range from $425 \mathrm{~m} / \mathrm{s}$ at $161-\mathrm{m}$ elevation to $180 \mathrm{~m} / \mathrm{s}$ at $195-\mathrm{m}$ elevation. Within this range of elevations at drill hole 69, the sediments consist of sand, fine gravel and sand, coarse gravel and sand, and soil. Such sediments typically have measured $S$-wave velocities that range approximately from 75 to $700 \mathrm{~m} / \mathrm{s}$ (Suyama and others, 1988; Williams and others, 2000), and their velocities typically increase with depth because the stress increases (Hunter, 1998; Zimmer and others, 2007). Consequently, this top composite layer is interpreted as alluvium.

The bottom layer, which is needed to interpret the refraction velocities, corresponds to the bottom layer in the geologic cross section (pl. 3). Within this layer, the $S$-wave velocities are about $2,500 \mathrm{~m} / \mathrm{s}$ and are confined to elevations approximately between 150 and $161 \mathrm{~m}$. The driller's log for hole 69 does not record the bedrock; hence, the top of the bedrock must be below about 164 m elevation. The bedrock is the Devonian limestone and dolomite (fig. 1); limestone has 
measured $S$-wave velocities that range approximately from 2,490 to 3,590 m/s (Press, 1966, p. 202; Domenico, 1984; Wilkens and others, 1984; Wang, 2002), and dolomite has measured $S$-wave velocities that range approximately from 3,000 to $3,500 \mathrm{~m} / \mathrm{s}$ (Wang, 2002). Consequently, this bottom layer is interpreted as the limestone and dolomite bedrock.

The refraction velocities in $G G^{\prime}$ and $C C^{\prime}$ are practically identical to those in $A A^{\prime}$, with one exception. The exception is at the very top, near 195-m elevation, where the velocities are as low as $110 \mathrm{~m} / \mathrm{s}$. Here, the ground is covered with soil that has not been compacted. Because such soils typically have measured $S$-wave velocities that range approximately from 75 to 300 m/s (Kudo and Shima, 1970; Suyama and others, 1988), the low velocities at the very top probably are due to the uncompacted soil.

\section{P-wave Refraction Profiles}

In profile $F F^{\prime}$ (pl. 3), the $P$-wave refraction velocities appear as three distinct layers. In the top layer, which ranges approximately from 193- to 195-m elevation, the velocities are about $250 \mathrm{~m} / \mathrm{s}$. The driller's log for hole 56 indicates that the sediments at these elevations consist of soil and coarse gravel and sand. Because this layer is above the water table (pl. 2), it is unsaturated. Such unsaturated, unconsolidated sands typically have measured $P$-wave velocities that range approximately from 50 to $700 \mathrm{~m} / \mathrm{s}$ (Bachrach and others, 1998; Zimmer and others, 2007). Consequently, this top layer is interpreted as unsaturated alluvium and unsaturated soil, and in the geologic cross section this layer is represented by the very top of the alluvium and the soil.

In the middle layer of profile $F F^{\prime}$, which ranges approximately from 160 - to 193 -m elevation, the $P$-wave velocities are about $1,800 \mathrm{~m} / \mathrm{s}$ (pl. 3). The driller's log for hole 56 indicates that the sediments at these elevations consist of sand with a trace of gravel, sand, fine gravel and sand, and coarse gravel and sand. Because this layer is below the water table (pl. 2), it is saturated. Such saturated, unconsolidated sediments typically have measured $P$-wave velocities that range approximately from 1,700 to 2,200 m/s (Hamilton, 1971; Zimmer and others, 2007). Consequently, this middle layer is interpreted as saturated alluvium, and in the geologic cross section this layer is represented by alluvium, except its very top.

In the bottom layer of profile $F F^{\prime}$, which ranges approximately from 157 - to 160 -m elevation, the $P$-wave velocities are about 5,000 m/s (pl. 3). The driller's log for hole 56 does not record the bedrock; hence, the top of the bedrock must be below 164-m elevation. The bedrock is the Devonian limestone and dolomite (fig. 1); limestone typically has measured $P$-wave velocities that range approximately from 1,700 to 7,100 m/s (Press, 1966, p. 202; Domenico, 1984; Wilkens and others, 1984; Wang, 2002), and dolomite typically has measured $P$-wave velocities that range approximately from 3,500 to $6,900 \mathrm{~m} / \mathrm{s}$ (Press, 1966, p. 203; Wang, 2002). Consequently, this bottom layer is interpreted as the limestone and dolomite bedrock, and in the geologic cross section this layer is simply represented by the bedrock.

In profile $D D^{\prime}$, the $P$-wave velocities appear as two distinct layers, which correspond to the top and middle layers in $F F^{\prime}$ (pl. 3). Because the interpretations of these two layers in $D D^{\prime}$ are the same as those in $F F^{\prime}$, the interpretations are not repeated. The significant difference between $D D^{\prime}$ and $F F^{\prime}$ is their thickness: $D D^{\prime}$ is merely $7 \mathrm{~m}$ thick, whereas $F F^{\prime}$ is about $45 \mathrm{~m}$ thick. In other words, the recorded waves probed to a depth of about $7 \mathrm{~m}$ for $D D^{\prime}$ but to a depth of about $45 \mathrm{~m}$ for $F F^{\prime}$. The reason for this difference is the amount of energy supplied by the sources: For $D D^{\prime}$, the amount was relatively small because the source was the 9.1-kg sledgehammer. In contrast, for $F F^{\prime}$, the amount was relatively large because the source was the truck-mounted weight drop (table 4).

\section{Consistency of Interpretations}

The results from each geophysical method were interpreted individually. Nonetheless, individual interpretations along parallel profiles referred to the same geologic cross section. For example, both the interpretation of the $S$-wave reflection image along $G G^{\prime}$ and the interpretation of the electrical resistivity along $C C^{\prime}$ referred to the geologic cross section along $C C^{\prime}$ (pl. 3). Thus, the individual interpretations are consistent with one another.

Consider just the four geologic cross sections shown on plate 3 . All cross sections have the same general stratigraphy: soil, alluvium, and bedrock. The soil is 1 to $2 \mathrm{~m}$ thick throughout the site; the alluvium is about $28 \mathrm{~m}$ thick at the northern end of the site (cross sections $A A^{\prime}, B B^{\prime}$, and $C C^{\prime}$ ) and about $25 \mathrm{~m}$ thick at the southern end of the site (cross section $\mathrm{HH}^{\prime}$ ). Thus, the four geologic cross sections are consistent with one another.

\section{Conclusions and Implications}

The results of the field demonstrations are summarized in table 5, which indicates whether a geologic or hydrologic feature was detected or measured by a particular geophysical method. Because the results have been discussed in the section "Interpretation," only a few remarks are necessary. Table 5 indicates that each geophysical method detected some of the major geologic and hydrologic features associated with the alluvial aggregate deposit, but no method detected all features. The implication is that no geophysical method should be expected to characterize all features of a deposit of alluvial aggregate. Rather, the criterion for selecting a particular geophysical method should be its suitability for characterizing the important features of the deposit. No geophysical method detected the clay layer at the bottom of the alluvium (table 5). Nonetheless, a clay layer might be detectable if the stratigraphy were different. For example, if the clay layer were thick and embedded in the middle of the alluvium, then it might 
be detectable with electrical resistivity profiling. The $S$-wave reflection profiling mapped the interface between layers with different grain sizes, and this method might be used to map such interfaces in other alluvial deposits.

The importance of these field demonstrations is that the results, which are summarized in table 5, indicate which geophysical methods might be used to characterize other alluvial aggregate deposits. For example, if information about stratigraphy is needed and a road is adjacent to the deposit, then $S$-wave reflection profiling might be helpful. If information about the topography of the bedrock is needed, then electrical resistivity profiling or most of the seismic methods might be helpful.

The information in table 5 must be used with caution. Whether a geophysical method can detect a particular geologic or hydrologic feature depends upon the underlying physical principles of the method, which are briefly summarized in the section "Geophysical Surveys." Detection depends upon the quality and the capabilities of the geophysical equipment that is used to collect the data, of the software that is used to process the data, and of the software that is used to interpret the data. With time, the quality and the capabilities of the equipment and the software will likely improve. Thus, the geophysical methods that are currently incapable of detecting a particular geologic feature might be capable of detecting that feature in the future. Detection depends upon the geology, the hydrology, and various features such as electric power lines, roads, and fences - all of these factors vary significantly from site to site. Detection also depends upon those who collect, process, and interpret the data. Accounting for all of these factors requires experience.

Although the time-domain electromagnetic soundings did not work well at this site, the method has worked well in some alluvial valleys, such as in Colorado where the bedrock is shale (Ellefsen and others, 1998). That is, this method can accurately estimate the thickness of an alluvial aggregate deposit if the alluvium has a high electrical resistivity and the layer beneath it has a low resistivity. Thus, this method should be considered when characterizing other alluvial aggregate deposits.

\section{Acknowledgments}

The Mineral Resources Program of the U.S. Geological Survey funded the portion of this project that involved USGS personnel.

Table 5. Summary of the field demonstrations, indicating whether a geologic or hydrologic feature was detected or measured by each geophysical method.

\begin{tabular}{ccccc}
\hline $\begin{array}{c}\text { Geophysical } \\
\text { method }\end{array}$ & Water table & $\begin{array}{c}\text { Geologic or hydrologic feature } \\
\text { Gravel and sand } \\
\text { layers within the } \\
\text { alluvium }\end{array}$ & $\begin{array}{c}\text { Clay layer at } \\
\text { the bottom of } \\
\text { alluvium }\end{array}$ & $\begin{array}{c}\text { Thickness of } \\
\text { alluvium }\end{array}$ \\
\cline { 2 - 5 } $\begin{array}{c}\text { Time-domain } \\
\text { electromagnetic } \\
\text { (TEM) sounding }\end{array}$ & No & No & No & Partly $^{1}$ \\
$\begin{array}{c}\text { Electrical resistivity } \\
\text { profiling }\end{array}$ & No & Partly & No & Yes \\
$\begin{array}{c}S \text {-wave reflection } \\
\text { profiling along } \\
\text { road }\end{array}$ & No & Yes $^{3}$ & No & Yes \\
$\begin{array}{c}S \text {-wave reflection } \\
\text { profiling in field }\end{array}$ & No & No & No & Yes \\
$\begin{array}{c}S \text {-wave refraction } \\
\text { profiling }\end{array}$ & No & No & No & Yes \\
$\begin{array}{c}P \text {-wave refraction } \\
\text { profiling with } \\
\text { sledgehammer } \\
\text { source }\end{array}$ & Yes & No & No & No \\
$P$-wave refraction \\
profiling with \\
$\begin{array}{c}\text { truck-mounted } \\
\text { source }\end{array}$ & Yes & No & No & Yes \\
\hline
\end{tabular}

${ }^{1}$ In the TEM models, the top layer may be interpreted as the alluvium, although its thickness differs considerably from the driller's logs.

${ }^{2}$ When the electrode spacing was $0.5,1.0,2.0$ and $3.0 \mathrm{~m}$, the electrical resistivity cross sections included anomalies at the ground surface that were interpreted as lenses of sand or gravel.

${ }^{3}$ The reflection profiling detected an interface between a layer of fine gravel with sand and another layer of sand. 


\section{References Cited}

AGI, 2003, EarthImager 2D, Resistivity and IP inversion software instruction manual: Austin, Texas, Advanced Geosciences Inc., 92 p.

Bachrach, Ran, Dvorkin, Jack, and Nur, Amos, 1998, Highresolution shallow-seismic experiments in sand, Part IIVelocities in shallow unconsolidated sand: Geophysics, v. 63 , no. 4 , p. 1234-1240.

Bates, R.L., and Jackson, J.A., 2005, Glossary of geology: Falls Church, Virginia, American Geological Institute, $800 \mathrm{p}$.

Benjumea, B., Hunter, J.A., Burns, R.A., Good, R.L., and Pullen, S.E., 2001a, Use of high-resolution shear-wavereflection methods for determining earthquake fundamental site period response near Alfred, Ontario: Geological Survey of Canada, Current Research 2001-D3, 6 p.

Benjumea, B., Pullen, S.E., Hunter, J.A., Burns, R.A., Douma, M., and Eaton, D., 2001b, Near-surface seismic methods applied to site-response characterization at an earthquake monitoring station near London, Ontario: Geological Survey of Canada, Current Research 2001-E7, 9 p.

Dobrin, M.B., and Savit, C.H., 1988, Introduction to geophysical prospecting, fourth ed.: New York, McGraw-Hill Book Company, $867 \mathrm{p}$.

Domenico, S.N., 1984, Rock lithology and porosity determination from shear and compressional wave velocity: Geophysics, v. 49, no. 8, p. 1188-1195.

Ellefsen, K.J., Lucius, J.E., and Fitterman, D.V., 1998, An evaluation of several geophysical methods for characterizing sand and gravel deposits: U.S. Geological Survey Open-File Report 98-221, 26 p.

Ellefsen, K.J., Tuttle, G.J., Williams, J.M., and Lucius, J.E., 2005, $S$-wave refraction survey of alluvial aggregate: U.S. Geological Survey Scientific Investigations Report 2005-5012, accessed July 30, 2007, and available at http://igs.indiana.edu/geology/maps/statephysiography/ physiography.cfm

Fitterman, D.V., and Labson, V.F., 2005, Electromagnetic induction methods for environmental problems, in Butler, D.K., ed., Near surface geophysics, Part 1-Concepts and fundamentals: Tulsa, Society of Exploration Geophysicists, p. 295-349.

Gray, H.H., 2000, Physiographic divisions of Indiana: Indiana Geological Survey Special Report 61, plate 1; accessed July 30, 2007, and available at http://igs.indiana.edu/ geology/maps/statephysiography/physiography.cfm
Hamilton, E.L., 1971, Elastic properties of marine sediments: Journal of Geophysical Research, v. 76, no. 2, p. 579-604.

Hasbrouck, W.P., 1983, Sketches of a hammer-impact, spikedbase, shear-wave source: U.S. Geological Survey Open-File Report 83-917, 7 p.

Hohmann, G.W., and Raiche, A.P., 1988, Inversion of controlled-source electromagnetic data, in Nabighian, M.N., ed., Electromagnetic methods in applied geophysics: Tulsa, Society of Exploration Geophysicsts, p. 469-503.

Hunter, J.A., 1998, Shear-wave velocity measurements for earthquake hazards studies, Frasier River delta, British Columbia, in Bell, R.S., Powers, M.H., and Lawson, T., eds., Proceedings of the Symposium on the Application of Geophysics to Engineering and Environmental Problems, March 22-26, 1998, Chicago, Illinois: Environmental and Engineering Geophysical Society, p. 459-469.

Indiana University, 1986, General stratigraphic column for Paleozoic rocks in Indiana: The Trustees of Indiana University; accessed July 30, 2007, and available at http://igs.indiana.edu/geology/structure/bedrockgeology/ index.cfm

Indiana University, 2005, Indiana geology-Indiana Quaternary geology map: The Trustees of Indiana University; accessed July 30, 2007, and available at http://igs.indiana.edu/geology/maps/statesurficial/ quaternaryGeology.cfm

Kaufman, A.A., and Keller, G.V., 1983, Frequency and transient sounding: Amsterdam, Elsevier, 685 p.

Kudo, Kazuyoshi, and Shima, Etsuzo, 1970, Attenuation of shear waves in soil: Bulletin of the Earthquake Research Institute, v. 48, p. 145-158.

Maier, R.D., 2004, Bedrock aquifer systems of Bartholomew County, Indiana: Indiana Department of Natural Resources, Division of Water, Resource Assessment Section, 1 sheet; accessed July 30, 2007, and available at http://www. in.gov/dnr/water/ground_water/ground_water_assessment/ bartholomew/pdf/bartholomew_bedrock.pdf

McNeill, J.D., 1990, Use of electromagnetic methods for groundwater studies, in Ward, S.H., ed., Geotechnical and environmental geophysics: Tulsa, Society of Exploration Geophysicists, p. 191-218.

National Cooperative Soil Survey, 2002, Soil survey of Bartholomew County, Indiana: United States Department of Agriculture, Natural Resources Conservation Service, 753 p. plus maps; accessed July 30, 2007, and available at http://www.in.nrcs.usda.gov/mlra11/manuscript_ publications/manuscripts.html 
Pelton, J.R., 2005, Near-surface seismology-Surface-based methods, in Butler, D.K., ed., Near surface geophysics, part 1-Concepts and fundamentals: Tulsa, Oklahoma, Society of Exploration Geophysicists, p. 219-263.

Press, Frank, 1966, Seismic velocities, in Clark, S.P., Jr., Handbook of physical constants (revised ed.): New York, Geological Society of America, p. 195-218.

Reynolds, J.M., 1997, An introduction to applied and environmental geophysics: Chichester, England, John Wiley \& Sons, 796 p.

Rupp, J.A., 1997, Tectonic features of Indiana: South Bend, Indiana, The Trustees of Indiana University; accessed July 30, 2007, and available at http://igs.indiana.edu/ geology/structure/tectonicfeatures/index.cfm

Suyama, K., Imai, T., Ohtomo, H., Ohta, K., and Takahashi, T., 1988, Delineation of structures in alluvium and diluvium using $S H$-wave reflection and VSP methods in Danbom, S.H., and Domenico, S.N., eds., Shear-wave exploration: Tulsa, Oklahoma, Society of Exploration Geophysicists, p. $165-179$.

Telford, W.M., Geldart, L.P., and Sheriff, R.E., 1990, Applied geophysics, second ed.: Cambridge, England, Cambridge University Press, 770 p.

Thompson, T.A., 1996, Bedrock geology of Indiana: South Bend, Indiana, The Trustees of Indiana University; accessed July 30, 2007, and available at http://igs.indiana.edu/ geology/structure/bedrockgeology/index.cfm

Wang, Zhijing, 2002, Seismic anisotropy in sedimentary rocks, part 2-Laboratory data: Geophysics, v. 67, no. 5, p. 1423-1440.

Ward, S.H., and Hohmann, G.W., 1988, Electromagnetic theory for geophysical applications, in Nabighian, M.N., ed., Electromagnetic methods in applied geophysics: Tulsa, Oklahoma, Society of Exploration Geophysicists, p. 131-312.

Wilkens, Roy, Simmons, Gene, and Caruso, Lou, 1984, The ratio $\mathrm{V}_{\mathrm{p}} / \mathrm{V}_{\mathrm{s}}$ as a discriminant of composition for siliceous limestones: Geophysics, v. 49, no. 11, p. 1850-1860.

Williams, R.A., Stephenson, W.J., Frankel, A.D., Cranswick, E., Meremonte, M.E., and Odum, J.K., 2000, Correlation of 1 - to $10-\mathrm{Hz}$ earthquake resonances with surface measurements of $S$-wave reflections and refractions in the upper $50 \mathrm{~m}$ : Bulletin of the Seismological Society of America, v. 90 , no. 5 , p. $1323-1331$.

Yilmaz, Özdo an, 1987, Seismic data processing: Tulsa, Oklahoma, Society of Exploration Geophysicists, 526 p.
Zimmer, M.A., Prasad, M., Mavko, G., and Nur, A., 2007, Seismic velocities of unconsolidated sands, Part 1-Pressure trends from 0.1 to $20 \mathrm{MPa}$ : Geophysics, v. 72, no. 1, p. E1-E13.

Zohdy, A.A.R., Eaton, G.P., and Mabey, D.R., 1974, Application of surface geophysics to ground-water investigations: U.S. Geological Survey, Techniques of Water-Resources Investigations, book 2, chap. D1, $116 \mathrm{p}$.

Zonge, Ken, Winn, Jeff, and Urquhart, Scott, 2005, Resistivity, induced polarization, and complex resistivity, in Butler, D.K., ed., Near surface geophysics, Part 1-Concepts and fundamentals: Tulsa, Oklahoma, Society of Exploration Geophysicists, p. 265-300.

\section{References to Previous Investigations of Alluvial Aggregate}

Anderson, Heather, 2000, Aggregate resource evaluation for a portion of Felton Prairie, Clay County, Minnesota: Minnesota Department of Natural Resources, Division of Lands and Minerals, Project 334-11, 82 p.

Auton, C.A., 1992, The utility of conductivity surveying and resistivity sounding in evaluating sand and gravel deposits and mapping drift sequences in northeast Scotland: Engineering Geology, v. 32, p. 11-28.

Barnett, Adrienne, and Ellefsen, K.J., 2000, Assessment of the alluvial sediments in the Big Thompson River valley, Colorado: U.S. Geological Survey Digital Data Series, DDS-66, 1 CD-ROM.

Crimes, T.P., Chester, D.K., Hunt, N.C., Lucas, G.R., Mussett, A.E., Thomas, G.S.P., and Thompson, A., 1994, Techniques used in aggregate resource analysis of four areas of the UK: Quarterly Journal of Engineering Geology, v. 27, part 2, p. 165-192.

Ellefsen, K.J., Lucius, J.E., and Fitterman, D.V., 1999, Geophysics in exploration for sand and gravel, in Johnson, K.S., ed., Proceedings, 34th Forum on the Geology of Industrial Minerals, May 2-6, 1998, Norman, Oklahoma: Oklahoma Geological Survey Circular 102, p. 147-149.

Ellefsen, K.J., and Barnett, Adrienne, 2001, An investigation of alluvial sediments using S-wave refraction-A case study, in Proceedings of the Symposium on the Application of Geophysics to Engineering and Environmental Problems, March 4-7, 2001, Denver, Colorado: Environmental and Engineering Geophysical Society, published on CD-ROM.

Jacobson, R.P., 1955, Geophysical case history of a commercial gravel deposit: Mining Engineering, v. 7, p. 158-162. 
Jol, H.M., Parry, D., and Smith, D.G., 1998, Ground penetrating radar-Applications in sand and gravel exploration, in Bobrowsky, P.T., ed., Aggregate resources-A global perspective: Rotterdam, A.A. Balkema, Inc., p. 295-306.

Middleton, R.S., 1977, Ground and airborne geophysical studies of sand and gravel in the Toronto region: Ontario Geological Survey Study GS18, 37 p.

Odum, J.K., and Miller, C.H., 1988, Geomorphic, seismic, and geotechnical evaluation of sand and gravel deposits in the Sheridan, Wyoming, area: U.S. Geological Survey Bulletin $1845,32 \mathrm{p}$.

Saarenketo, T., and Maijala, P., 1994, Applications of geophysical methods to sand, gravel and hard rock aggregate prospecting in northern Finland, in Lüttig, G.W., ed., Aggregates-Raw materials giant: Report on the $2 \mathrm{~d}$ International Aggregates Symposium, Erlangen, Germany, October 22-27, 1990, p. 109-123.

Singhroy, V.H., and Barnett, P.J., 1984, Locating subsurface mineral aggregate deposits from airborne infrared imagery (reflected and thermal)_A case study in southern Ontario, in Proceedings of the International Symposium on Remote Sensing of the Environment, 3d Thematic Conference: Remote Sensing for Exploration Geology, p. 523-539.

Wilcox, S.W., 1944, Sand and gravel prospecting by the earth resistivity method: Geophysics, v. 9, p. 36-46. 